\title{
Convergencias y divergencias en el orden normativo estadounidense: una interpretación constructivista de la relación política sino-estadounidense
}

\author{
Convergences and Divergences in the American \\ Normative Order: A Constructivist Interpretation of the \\ Sino-American Political Relationship
}

DOI: $10.32870 /$ mycp.v9i25.620

José Jesús Bravo Vergara ${ }^{1}$

\begin{abstract}
Resumen
El objetivo de este artículo es explicar cómo Estados Unidos aprovechó las divergencias sino-soviéticas para acercarse a Pekín no solo con el fin de contener a Moscú en Asia Central, sino también de incorporar a China a una normatividad internacional a fin de abrirlo al libre comercio y democratizarlo en un orden que le favorecía. No obstante, aunque en la normatividad internacional que dirige Estados Unidos tuvo éxito en la contención soviética y en la apertura china al comercio, fracasó en democratizar a Pekín. Además, si bien el actual orden internacional estadounidense ha beneficiado a China en el rubro de lo económico, ahora Washington corre el riesgo de que la magnitud de los intereses de Pekín se dirijan a promover una nueva normatividad internacional.

El análisis se realiza con base en el Constructivismo de las Relaciones Internacionales enfocado en las normas e identidades que hacen énfasis en los valores de los países dominantes.
\end{abstract}

Palabras clave: Normatividad, orden internacional, constructivismo, China, Estados Unidos.

\begin{abstract}
The objective of this article is to explain how the United States took advantage of the Sino-Soviet divergences to approach Beijing not only within order to contain Moscow in Central Asia, but also to incorporate China into an international norm to open it to free trade and democratize it in an order that favored it. However, although in the international normativity that the United States guided, it was successful in the Soviet containment and the Chinese opening to trade, it failed to democratize in Beijing. Also, while the current US international order has benefited China in the economic field, now Washington faces the risk that the magnitude of Beijing's interests will be aimed to promote a new international norm.

The analysis is carried out based on the Constructivism of International Relations, focused on the norms and identities that emphasize the values of the dominant countries.
\end{abstract}

Keywords: Normativity, International Order, Constructivism, China, United States.

Artículo recibido el 26 de febrero de 2019 y dictaminado el 04 de noviembre de 2019.

1. Universidad de Guadalajara, Departamento de Estudios del Pacífico. Av. Parres Arias 150, Los Belenes, Zapopan, Jalisco, México. ORCID: http://orcid.org/0000-0002-7176-314X Correo electrónico: braverjoje@hotmail.com 


\section{Introducción}

A inicios de la década de 1970 el gobierno de Estados Unidos se acercó al régimen chino aprovechando el alejamiento político-ideológico entre la República Popular de China (RPCh) y la Unión de Repúblicas Soviéticas Socialistas (URSS), así como los momentos de tensión militar fronteriza entre ambos gigantes socialistas en los ríos Amur y Ussuri. El entonces presidente estadounidense, Richard Nixon, procuró utilizar la confrontación ideológica y las escaramuzas fronterizas entre chinos y soviéticos para atraer a Pekín a su esfera de influencia. Hacia 1971, tras una votación en la Asamblea General de la Organización de Naciones Unidas (AGNU), la RPCh obtuvo un escaño para representar al pueblo y Estado chino en dicha organización al tiempo que la representación de la República de China (antes China Taipei, actual Taiwán) fue expulsada. Con ello quedó sellado el reconocimiento del régimen de Pekín como único representante del pueblo y Estado chino en detrimento de Taiwán. El 1 de enero de 1979, el gobierno del entonces presidente Jimmy Carter por fin hizo oficial el reconocimiento de Estados Unidos a la RPCh al tiempo que interrumpió las relaciones diplomáticas con el gobierno nacionalista. ${ }^{2}$

Desde el inicio de las relaciones diplomáticas con Pekín, Estados Unidos ha procurado influir políticamente a la RPCh a través de la apertura económicocomercial y de su inclusión en el orden normativo internacional dirigido por Washington. Ambos países se han visto beneficiados, al menos en una primera instancia, por dicha relación. Sin embargo, no solo la desaparición de la Unión Soviética a finales de 1991, sino el incesante crecimiento económico de la RPCh y la proyección de su economía, ha llevado a Estados Unidos a identificar a China como un competidor directo a su posición hegemónica en el orden internacional.

En este trabajo se pretende, a través de una contextualización histórica, así como de un análisis teórico constructivista, analizar la relevancia de un orden normativo en la relación sino-estadounidense y si dicho orden ha comenzado a presentar cambios en sus cimientos a partir del incremento del poder chino y de la expansión de sus intereses, sin que ello represente violentar o anular

2. Estados Unidos otorga a la RPCh el reconocimiento diplomático, admitiendo el principio de "Una sola China" y corta lazos diplomáticos con Taiwán. Asimismo, el Congreso aprueba la Ley de Relaciones con Taiwán que permite continuar las relaciones comerciales y culturales entre Estados Unidos y Taiwán. (Central Intelligence Agency, 1982). 
definitivamente el actual orden de las normas, con base en lo anterior se plantea la siguiente pregunta: ¿Qué resultados ha tenido la promoción del orden normativo liderado por Estados Unidos tras otorgarle su reconocimiento de la RPCh como único representante del pueblo y Estado chino? Asimismo, se propone la siguiente hipótesis con el fin de que sirva como hilo conductor en este artículo: El choque de intereses y las escaramuzas fronterizas entre Pekín y Moscú motivaron a Washington a otorgarle su reconocimiento a Pekín, no solo con el fin de sacar ventajas estratégicas, sino también con la meta de que China aceptara y adoptara el orden normativo estadounidense basado en la promoción y desarrollo de la democracia, así como del libre comercio, un planteamiento en el que Washington ha tenido éxito parcialmente.

Con ese objetivo, el trabajo ha sido dividido en ocho apartados: 1) El constructivismo: identidad, intereses y normas; 2) Estados Unidos durante la guerra civil china y la Guerra de Corea; 3) la atención estadounidense en el rompimiento sino-soviético: 1958 a 1969; 4) el establecimiento de la relación política sino-estadounidense durante la última década de la Guerra Fría: de Carter a Bush HW; 5) la relación política sino-estadounidense después del fin de la Guerra Fría: de Clinton a Trump; 6) Del conflicto a la convergencia: una visión constructivista; 7) Posguerra Fría y siglo Xxi: la aparición de nuevas divergencias y 8) Conclusiones.

\section{1) El constructivismo: identidad, intereses y normas}

La literatura de Relaciones Internacionales sobre la relación política entre Estados Unidos y la RPCh ha sido abundante desde la misma fundación de esta última a finales de 1949, y ha aumentado tras la instauración de la relación diplomática entre ambos países en 1979. Actualmente, las discusiones teóricas se centran en cómo Estados Unidos y China tomaron nuevas decisiones con respecto al desarrollo de su relación ante la caída de la URSS y el final de la Guerra Fría. En ese sentido, el análisis se concentra primero, en la interiorización por parte de la RPCh de la estructura normativa liderada por Estados Unidos, y posteriormente sobre la posibilidad de un probable replanteamiento de dicha estructura a partir de la demanda china de la consideración de sus intereses.

Desde una perspectiva marxista, se ataca a Estados Unidos como potencia hegemónica (Linklater, 1990, p.154). La explicación liberal se enfoca en que el régimen de Pekín vincula las reformas domésticas y el desarrollo 
económico con la necesidad de incrementar la confianza y la cooperación con Washington (Wenzao, 2004, p.410). En la perspectiva realista, en específico en el realismo estructural, se asume que el simple e incesante crecimiento de las capacidades materiales chinas está creando condiciones para una lucha por el poder con Washington (Waltz, 2000, p.32). Finalmente, la propuesta constructivista se enfoca en la competencia o la cooperación que puede desarrollarse entre ambas potencias con base en el desarrollo de sus identidades e intereses, así como en la práctica de principios normativos (Hung, 2013, pp.53-57). Precisamente, se recurre a la perspectiva constructivista debido a que se busca analizar la convergencia respecto de una identidad colectiva basada en normas que les motiva tanto a Estados Unidos así como a la RCPh a mantener una sociedad internacional estable de la cual se benefician en sus intereses centrales a pesar de que en dicha interacción también puedan encontrarse numerosas divergencias.

Robert Keohane reconoció la fuerza de aquellas explicaciones que concedían una gran estimación a los valores, las normas y las prácticas para comprender las instituciones en la política internacional y les llamó reflexivistas (Keohane, 1988, p.389). En 1989, Nicholas Onuf llamó Constructivismo a dichas explicaciones debido a que intentaban razonar sobre un nuevo orden que se estaba construyendo con el fin de la Guerra Fría (Onuf, 1989). Lo anterior ante la incapacidad del Neorrealismo y el Neoliberalismo para anticipar el fin de la era bipolar y los cambios que se presentaron con dicho evento, tales como la desintegración de la Unión Soviética.

El Constructivismo se consagró con los planteamientos de Alexander Wendt $(1992,1999)$ y Emannuel Adler (1997). En el caso de Wendt (1992), planteó que la anarquía no es necesariamente una propiedad conflictiva del sistema internacional, en todo caso, los Estados actúan conforme a sus intereses, es decir, metas a alcanzar, y que dichos intereses son a su vez, construcciones sociales a partir de las identidades. Asimismo, Wendt (1999) formuló una teoría estructural para la disciplina de las Relaciones Internacionales. Adler (1997), plantea a dicha perspectiva como una alternativa diferente a los enfoques racionalistas y le atribuye una mayor relevancia a lo ontológico (la definición del objeto de estudio) y lo epistemológico (la forma de acercarse al conocimiento) sobre lo metodológico, debido a que asume que ello contribuye a un mejor entendimiento de las Relaciones Internacionales: "El constructivismo detenta la visión en el que la forma del mundo material es formada por la acción humana cuya interacción depende de una dinámica normativa 
e interpretaciones epistémicas del mundo material" (Adler, 1997, p.322). En breve, lo material y lo social están intrínsecamente correlacionados e interactúan en la construcción social de la realidad (Santa-Cruz, 2000, p.163).

Una de las principales contribuciones del constructivismo es la problematización de las identidades, a las cuales considera una variable que depende del contexto histórico, cultural, político y social de los actores (Hopf, 1998, p.174), es decir, es el rasgo fundamental de cada actor o Estado que produce acción tanto al interior como en el exterior. Con base en ello, éstas ofrecen información sobre sus intereses -las metas de los Estados-, sus actitudes y el papel que buscarán desempeñar en el sistema internacional (Hopf, 1998, p.194). Según Henry Nau (2002), la identidad mide a una nación en términos no materiales y enfatiza en los factores que motivan el interés nacional, en resumen, son el rasgo fundamental que trata los valores desarrollados por un actor o Estado y que producen acción tanto al interior como al exterior de éste a través de la interacción social con otros actores o Estados (Jepperson, Wendt \& Katzenstein; 1996, pp.17-18), o como diría Wendt (1992), son inherentemente relacionales.

Wendt (1992), también señala que las identidades son la base de los intereses. A su vez, los intereses son las metas en pos de las que debe de ir la política exterior de un Estado, es decir, constituye la base de la acción social de un país (Weldes, 1996, p.276). Lo anterior implica que los intereses no son algo que deba ser descubierto por los actores (Estados), sino que se construyen a través de un proceso de interacción social en donde el papel que juega la identidad resulta esencial (Katzenstein, 1996, p. 2).

Por su parte, Yücel Bozdaglioglu (2003), explica que la identidad del Estado precede al interés y que los Estados no pueden decidir cuáles son dichos intereses hasta que no identifiquen qué es lo que representan para ellos. Si bien es cierto que los intereses se construyen con base en la identidad de un Estado, esto no significa que se ignoren los condicionamientos externos (Bravo \& Sigala, 2014, p.446), eso significa que los intereses constituyen una manifestación de las acciones y objetivos del Estado en función de su identidad y del lugar que ocupa en el sistema internacional (Weldes, 1996, p.280).

Los constructivistas también plantean que las identidades de los Estados se reconstituyen a partir de la interiorización y modificación de las normas sociales internacionales a través de las interacciones con otros Estados (Bravo \& Sigala, 2014, p.447). En el análisis de la política internacional, el constructivismo toma en cuenta el estudio de las normas pues sostiene que las 
estructuras normativas son muy relevantes debido a que son entendimientos compartidos o comunes, y por lo tanto, prácticas sociales que facilitan la mediación en la relación entre los Estados e influyen en la construcción de su identidad, lo que a su vez define en su momento, sus intereses particulares (Hobson, 2000, p.146).

Robert Keohane, señala que las normas conforman concepciones del interés propio de los Estados y pueden ser convenientes o inconvenientes en la medida en que dichos Estados buscan alcanzar sus intereses (Keohane, 2013, p.39). Ian Clark (2014), amplía esta explicación y menciona que las normas reflejan el poder de los países dominantes al socializar valores y patrones de comportamiento que tienen la capacidad de modificar la conducta de otros Estados. Éstos a su vez, las aceptan e interiorizan porque consideran que les proporcionan algunos beneficios (Clark, 2014, p.316). En ese sentido, Jeffrey Checkel señala que las normas no son solamente una constante en la reproducción de patrones de comportamiento e intereses de los Estados más poderosos, sino que también funcionan como reguladores de la actuación de los Estados en la escena internacional y ayudan a crear estructuras al tiempo que desarrollan una dinámica interactuante y mutuamente constituida (Checkel, 1998, p.328).

Ian Hurd (1999) va más lejos y señala que el cumplimiento de una norma puede estar motivado también por la creencia en su legitimidad, es decir, el valor que un Estado le atribuye a dicha norma como razón para su cumplimiento. Lo anterior implica entonces que un Estado cumplirá con una norma porque está motivado más por el sentido intrínseco de obligación moral y la percepción de la legitimidad de ese orden normativo, que por la coerción o, incluso, por simple interés propio (Hurd, 1999, p.387). Desde ese punto de vista, las normas pueden ser consideradas como procesos habilitadores que buscan alcanzar resultados cooperativos y benéficos con otros Estados, (Björkdahl, 2002, p.16), es decir, una serie de preceptos que ayudan a superar la posibilidad de conflictos.

En términos generales, los constructivistas sostienen que los sistemas de normas compartidas tienen características estructurales (Reus-Smit, 1996, p.207), y debido a que las realidades sociales son tan influyentes como las realidades tangibles, dichas estructuras normativas son tan importantes como las estructuras materiales (Finnemore, 1996, p.128). También nos brindan una alternativa que describe cómo la conducta de un Estado puede modificarse a partir de la aceptación de normas que encuentra estratégicamente relevantes 
para sus propios fines o que considera justas porque le permiten expresar de mejor forma sus intereses, así como construir una identidad que puede percibirse como demandante, pero también confiable $y$, por ende, tendiente a evitar el conflicto. En general, estas aportaciones sobre identidad, intereses y normas proponen bases de una alternativa constructivista en la explicación sobre los cuarenta años de la relación política sino-estadounidense.

\section{2) Estados Unidos durante la guerra civil china y la Guerra de Corea}

Tras el final de la Segunda Guerra Mundial (SGM), Estados Unidos tuvo la capacidad para traducir su poder material en influencia política y asumió el liderazgo en la promoción de un nuevo orden internacional respaldado en instituciones económicas y normas de convivencia internacional (Reus-Smit, 2004, pp.77-78). Precisamente, en el transcurso de la SGM, Washington ya había asumido la determinación de defenderse a sí mismo y a sus aliados. En el caso de China, apoyó al gobierno nacionalista en su lucha contra Japón. Para 1944, el entonces presidente Franklin D. Roosevelt, preocupado de que los constantes enfrentamientos entre el gobierno del Kuomitang (nacionalistas) y los comunistas afectaran la futura unificación china, instó al Kuomitang a establecer un acuerdo con estos últimos con el fin de centrar su atención en el enemigo japonés (Powaski, 2014, p.102). Asimismo, Roosevelt promovió al líder nacionalista Chiang Kai-shek, como uno de los protagonistas en la lucha mundial contra las potencias del Eje (May, 2002, p.1004). ${ }^{3}$

Al final de la guerra, el nuevo presidente estadounidense, Harry Truman, exigió a las fuerzas japonesas en China -salvo las desplegadas en Manchuria-, rendirse solo a las tropas nacionalistas chinas; ordenó a su Comandante en el país asiático, Albert C. Wedemeyer, apoyar el traslado de las mejores divisiones del Kuomitang a las ciudades chinas ocupadas por los japoneses con el fin de aventajar a las tropas comunistas, además proporcionó 3,000 millones de dólares y material de guerra al gobierno de Chiang Kai-shek (Powaski, 2014, p.104). No obstante, Truman trató de impedir que se reanudara la guerra civil

3. Durante la Conferencia de El Cairo en noviembre de 1943, el entonces presidente estadounidense Franklin D. Roosevelt hizo mención de un orden de postguerra que sería mantenido por lo que denominó los cuatro policías: Estados Unidos, el Reino Unido, la Unión Soviética y la República de China. Asimismo, en la Conferencia de Yalta, presionó al líder soviético Joseph Stalin para que considerara a Chiang Kai-shek con el mismo estatus al de los “Tres Grandes" -Roosevelt, Stalin y Churchill- (May, 2002, p.1004). 
en China y que su país se viera involucrado en una confrontación indirecta con la URSS (Powaski, 2014, p.106; May, 2002, p.1003).

En noviembre de 1945, Truman envío al Jefe del Estado Mayor del Ejército de Estados Unidos, George Marshall, a mediar entre el Kuomitang y los comunistas (May, 2002, p.1004), pero no pudo concretar nada, y para junio de 1946 Chiang Kai-shek optó por una guerra total contra los comunistas (Lynch, 2008, p.9). Con un ejército inicialmente más numeroso, el líder nacionalista asumió la idea de que el triunfo de su gobierno era inminente (Hsü, 2012). Sin embargo, en 1947 la ofensiva del Kuomitang se había debilitado y los comunistas comenzaron a ganar terreno en todo el país, al tiempo que el General Marshall, por órdenes de Truman, abandonó la misión mediadora (Hsü, 2012).

A inicios de 1949, y ante la arremetida imparable de los comunistas, Chiang Kai-shek mandó constantes misivas suplicando a Estados Unidos, su intervención militar. Sin embargo, el General Marshall, entonces Secretario de Estado, aconsejó a su gobierno que no se involucrara en la guerra civil china, pues asumía que cualquier esfuerzo de Estados Unidos implicaría obligaciones y responsabilidades extremas, y que ello a su vez, desviaría tanto su atención, así como sus recursos de Europa occidental, en un momento en que dicha región se encontraba amenazada ante embestida política soviética (May, 2002, p.1009). Con ello se selló la suerte del Kuomitang cuya dirigencia tuvo que huir a la isla de Taiwán.

Para el 1 de octubre de 1949, Mao Tse-tung proclamó la fundación de la República Popular de China y la URSs se convirtió en el primer país que reconoció al nuevo Estado (Powaski, 2014, p.108). Hacia febrero de 1950 ambos países firmaron el Tratado sino-soviético de Amistad, Alianza y Ayuda Mutua. Asimismo, los soviéticos facilitaron un empréstito por 300 millones de dólares, asesoría militar y apoyo logístico a Pekín, al tiempo que Mao declaró "la inclinación china hacia un lado" (Anguiano, 2001, p.192), ${ }^{4}$ y reconoció en Stalin y en la URSS, el liderazgo dentro del bloque comunista (Powaski, 2014, p.108).

Una vez terminado el episodio de la guerra civil en China, el 25 de junio de 1950 se dio la invasión de soldados norcoreanos a Corea del Sur con el fin de unificar la península bajo un régimen pro-soviético la cual provocó la alarma internacional. En respuesta, Estados Unidos convocó a una reunión

4. Mao señaló que su país tenía que ponerse del lado del comunismo pues no era posible "cabalgar" entre dos pisos y que no existía un "tercer camino" para su país (Anguiano, 2001, p.192). 
del Consejo de Seguridad de Naciones Unidas y ante la ausencia del Embajador soviético en dicho órgano, se aprobaron las resoluciones 82 y 83 en las que se demandaba el retiro de tropas norcoreanas de Corea del Sur. En dicha sesión, se aprobó también la Resolución 84, en la que se recomendaba a los países miembros de la Organización de Naciones Unidas (ONU) proporcionar fuerzas militares para liberar al país agredido. ${ }^{5}$ El General Douglas MacArthur fue nombrado Comandante de un ejército conformado por soldados de más de 15 países bajo la bandera de las Naciones Unidas (Malkasian, 2001, p.17). La respuesta militar promovida por Washington fue rápida y efectiva, de modo que para octubre de 1950, las tropas de la ONu habían tomado Pyongyang, y se dirigían a buscar el control absoluto de Corea del Norte.

El acercamiento de tropas estadounidenses a la frontera china preocupó seriamente a los líderes de la RPCh, pues entendían que una victoria de Washington y sus aliados en la península coreana pondría en peligro su seguridad, así como sus intereses ideológicos, por lo que reaccionó enviando a Corea del Norte unidades del Ejército Popular de Liberación (EPL) con el apelativo de "Voluntarios del Pueblo Chino" el 15 de octubre de 1950 (Jian, 1994, p.175).

Asimismo, la URSS también intervino en el conflicto de forma no oficial a través del envío de armamento y apoyo militar aéreo (Malkasian, 2001, p.28). Gracias a ello, la Guerra de Corea se transformó en "la primera guerra caliente" de la Guerra Fría, una situación que subió de tono debido a que ante la impotencia de poder ganar la confrontación de forma rápida, el General MacArthur amenazó con utilizar bombas atómicas contra las tropas chinas en Corea y con ampliar la guerra en territorio chino (Stueck, 1995, pp.134-149). La noticia de esta amenaza fue considerada como algo sumamente peligroso si se toma en cuenta que, desde septiembre de 1949, Moscú había anunciado la posesión de armamento atómico y podría utilizarlo como represalia si Washington atacaba a la RPCh con su poder atómico. Con este escenario, el presidente Truman asumió la necesidad de evitar una guerra total en Corea, y ante la imprudencia de MacArthur le destituyó como comandante de las fuerzas de Naciones Unidas y nombró al General James Van Fleet Ridway como su sucesor (Stueck, 1995, p.170).

La intensificación de la confrontación militar, así como el estancamiento geoestratégico militar al interior de la península, obligaron a ambas partes a negociar un cese al fuego que entró en vigor el 27 de julio de 1953 (Flint,

5. Naciones Unidas (1950). 
Kozumplik, \& Waraksa, 1987, p.120). De esta forma, si bien es cierto que los planes iniciales avalados por Moscú y Pekín de unificar toda Corea bajo un gobierno pro-comunista no pudieron concretarse, tampoco los estadounidenses pudieron liberar toda la península y el bastión comunista permaneció en el norte.

\section{3) La atención estadounidense en el rompimiento sino-soviético:} 1958 a 1969

La mancuerna sino-soviética comenzó a verse desgastada cuando tras el discurso del nuevo líder del Partido Comunista de la Unión Soviética (PCUS), Nikkita Khruschev, en el xx Congreso del Partido Comunista de la Unión Soviética en febrero de 1956 (Li \& Xia, 2018, pp.8-21), denunció las deportaciones y ejecuciones sumarias que había cometido Stalin durante su régimen, una afirmación incómoda para la delegación china que reconocía en Stalin al líder del mundo comunista (Lüthi, 2008, p.46).

La divergencia entre Pekín y Moscú subió de tono debido a que los ejercicios militares realizados por el ELP en el Estrecho de Taiwán entre agosto y septiembre de 1958 provocaron la movilización de la séptima flota estadounidense en defensa del gobierno nacionalista apostado en Taiwán, lo que a su vez, llevó al Kremlin a que advirtiera a Washington que se consideraría cualquier ataque contra la RPCh como una agresión contra la propia Unión Soviética en lo que se conoció como la Segunda Crisis del Estrecho de Taiwán (Roy, 1997, p.23). ${ }^{6}$ Si bien es cierto que ante el mundo Khruschev mostró su firmeza al disuadir a Estados Unidos de ir más lejos en su movilización naval, en privado, el líder soviético advirtió a sus homólogos chinos que el Ejército Rojo no respaldaría una nueva provocación del régimen de Pekín contra los nacionalistas y contra Estados Unidos (Anguiano, 2001, p.221).

La reacción de Mao Tse-Tung frente al planteamiento de su aliado fue de inconformidad. En primer lugar, Mao criticó a Khruschev su política de coexistencia pacífica con Occidente, pues para la RPCh era necesario iniciar de forma violenta una lucha de clases contra la burguesía mundial (Lüthi,

6. En un memorándum enviado por el Kremlin a la Casa Blanca, la Unión Soviética advertía a Estados Unidos que la RPCh era un gran amigo, aliado y vecino de su país y que cualquier ataque contra la RPCh sería considerado como un ataque contra la Unión Soviética por lo que haría todo con el fin de defender junto a China, la seguridad de ambos Estados y los intereses de la paz en el mundo entero (Halperin, 1966, p.315). 
2008, pp.80-81). En segundo lugar, denunció que esta posición de Moscú respaldaba indirectamente la existencia del gobierno nacionalista en Taiwán (Basrur, 2008, p.25). De la misma forma, Mao también demandó que Moscú no había accedido a ayudar a la RPCh a fabricar submarinos nucleares, ni a cumplir con la asistencia para la fabricación de armas nucleares a sabiendas de que Pekín precisaba de su apoyo para modernizar sus fuerzas armadas (Zubok \& Pleshakov, 1996, p.217). ${ }^{7}$ Incluso se señaló que Moscú buscaba controlar a Pekín a través de la formación de una flota conjunta de submarinos que estuviera instalada en algunos puertos e islas chinas (Garver, 2003, pp.205-206). ${ }^{8}$

La continuidad de divergencias ideológicas entre ambos Estados y la identificación por parte de Moscú de la sensibilidad nacionalista china, a la que consideraba imprudente y desconfiada, provocó que Krushshev dudara sobre la pertinencia de compartir la posesión de la bomba nuclear táctica, aun cuando ésta ya estaba lista y a punto de ser enviada a China. Por ese motivo, tras una reunión del Presídium del PCUs, se decidió que no se les proporcionaría a los chinos el prototipo de la bomba (Zubok \& Pleshakov, 1996, p.228). Esta situación y la posterior cancelación del programa nuclear sino-soviético, así como el retiro de un gran número de asesores soviéticos de diferentes programas de desarrollo en territorio chino produjeron un fuerte golpe en la relación bilateral.

En octubre de 1962 se presentaron dos eventos sumamente relevantes en la relación sino-soviética: la guerra sino-india y la crisis de los misiles soviéticos en Cuba. En el caso de la guerra sino-india, Pekín reclamaba a su vecino el territorio de Aksai-Chin, una zona en el límite oriental de la línea McMahon que impuso el imperio británico a principios del siglo xx y que India había conservado tras su independencia en 1947. Debido a ese reclamo se inició un conflicto armado el 20 de octubre de ese año, en plena crisis por la instalación de misiles nucleares soviéticos en Cuba.

7. El 27 de abril de 1955 los gobierno de la RPCh y la URSS firmaron un acuerdo de asistencia nuclear titulado "Sobre la prestación de la asistencia de la URSS a la República Popular de China en materia de desarrollo de estudios sobre física del núcleo atómico y sobre la utilización de energía nuclear para las necesidades de la economía popular" (Zubok \& Pleshakov, 1996, p.217).

8. Zubok \& Pleshakov (1996) señalan que la dirigencia china consideraba inaceptable la propuesta de Moscú, pero que lejos de querer controlar a la RPCh, la URSs precisaba del desarrollo de una flota naval conjunta para contrarrestar de forma efectiva a la séptima flota estadounidense estacionada en la zona del Pacífico. 
Durante el conflicto, que duraría alrededor de un mes, Pekín esperó algún pronunciamiento soviético a su favor al tiempo que apoyó las acciones soviéticas en el Caribe; sin embargo, los pronunciamientos soviéticos en respaldo a la RPCh fueron poco claros. Asimismo, si bien es cierto que por un lado el régimen chino habría estado satisfecho con la permanencia de los misiles soviéticos en Cuba porque ello demostraría que era correcta su percepción de aplicar el principio de presión al imperialismo estadounidense, también lo fue el hecho de que la dirigencia china devolvió la llamada de atención que el Kremlin había hecho a Pekín durante la crisis del Estrecho de Taiwán, pues en esta ocasión, con sus acciones, la URSS habría involucrado en una guerra indeseada no solo a la RPCh, sino también al resto de sus aliados (Prozumenschikov, 1996-1997, p.256). ${ }^{9}$ Con este pronunciamiento, el régimen de Pekín no solo mostró su crítica a las acciones de Moscú, sino también las condenó, un hecho que abonó aún más a la erosión de la relación bilateral.

A pesar de las divergencias, soviéticos y chinos continuaron cooperando con el gobierno de Vietnam del Norte en su lucha por unificar todo Vietnam bajo la bandera comunista y expulsar de ese país a su enemigo común: Estados Unidos (Roberts et al., 2010, p.123). No obstante, las diferencias fronterizas darían el tiro de gracia a las desgastadas relaciones sino-soviéticas. En febrero de 1964, Pekín y Moscú comenzaron negociaciones sobre la frontera que se extiende desde Vladivostok hasta Mongolia, incluyendo los ríos Ussuri, Amur y Argún. Por un lado, desde el punto de vista oficialista, la RPCh no pedía que la URSS le regresara territorio, pero sí que reconociera que los antiguos tratados zaristas con la Dinastía Qing habían sido desiguales y que la URSS se había beneficiado de ellos (Lüthi, 2008, p.276). ${ }^{10}$ Por su parte, algunos archivos soviéticos señalan que el régimen de Mao le exigió a Moscú el retorno de Vladivostok y las tierras al este del río Ussuri y al norte del río Amur (Lüthi, 2008). De hecho, en una declaración realizada el 13 de junio de

9. En su crítica al Kremlin por la instalación de misiles nucleares en Cuba, la dirigencia china reclamó a Moscú la necesidad de compartir información a sus aliados, el mismo argumento utilizado por los soviéticos durante la Crisis del Estrecho de Taiwán en 1958 (Prozumenschikov, 1996-1997, p.256).

10. Durante la reunión celebrada en el aeropuerto de Pekín, el 11 de septiembre de 1969, el entonces Primer Ministro chino, Zhoun Enlai, señaló a su homónimo soviético, Alexander Kosygin, lo siguiente: Nosotros mencionamos aquellos tratados desiguales, no para una propuesta de abolirlos. Antes que nada nosotros tenemos la voluntad de reconocer esos tratados y creemos que China y la URSS deberían considerar y tratar las disputas territoriales con base en el reconocimiento de dichos tratados (Kuisong, 2000, p.38). 
1969, Moscú acusó al gobierno chino de aplicar una política expansionista (Frade, 1979, p.72).

El 2 de marzo de 1969 un contingente fronterizo chino abrió fuego contra una unidad del ejército soviético, ${ }^{11}$ y fueron repelidos por éste en la isla de Zhembao o Damansky, ${ }^{12}$ una de las islas del río Ussuri, causando numerosas bajas en ambas partes. ${ }^{13}$ Trece días después fuerzas de los dos países se volvieron a enfrentar en el mismo lugar, esta vez con más unidades militares y mayor potencia de fuego (Gerson, 2010, p.2). La represalia soviética fue con tal intensidad que causó alrededor de 800 bajas en el ejército chino en pocos días (Chang \& Halliday, 2005, p.1365). Asimismo, el Kremlin asumió la posibilidad de lanzar misiles nucleares contra las nacientes instalaciones nucleares chinas e incluso sondeó a la Casa Blanca sobre tal operación (Chang \& Halliday, 2005, p.1358), ${ }^{14}$ con el fin de que se mantuviera neutral. ${ }^{15}$ No obstante, el entonces presidente de Estados Unidos, Richard Nixon, advirtió que su país proporcionaría "un escudo" si una potencia nuclear amenazaba la libertad de una potencia aliada o de una nación cuya seguridad fuera considerada como relevante para Estados Unidos (Kissinger, 1979, pp.224-225). Por su parte, el entonces líder del PCUS, Leonid Breshnev se conformó con el despliegue nuclear y no fue más lejos (Basrur, 2008, p.27).

Nixon procuró utilizar la confrontación en el campo comunista para atraer a Pekín, y jugar la "carta china" con el fin de obtener concesiones en las negociaciones sobre la reducción de armas nucleares con la Unión Soviética, incluso en una carta enviada a por él a Mao en marzo de 1973, hizo un compromiso unilateral de intervenir militarmente si la URSS atacaba a la RPCh (Sinha,

11. U.S. DEPARTMENT OF STATE. (1969). Intelligence Note 139 (AuthorityNND909000). Recuperado de https://nsarchive2.gwu.edu//NSAEBB/NSAEBB49/sino.sov.1.pdf

12. La isla era llamada Zhembao por los chinos y Damansky por los soviéticos (Gerson, 2010, p. 2).

13. Según informes oficiales, las bajas soviéticas fueron de 31 soldados muertos y 14 heridos, mientras que las autoridades chinas no especificaron el número de bajas, solo señalaron que habían sido numerosas (Gerson, 2010, p.3).

14. Como ya se señaló, hacia octubre de 1969, la dirigencia soviética consideró la posibilidad de lanzar un ataque nuclear contra las rudimentarias fuerzas nucleares chinas, y se temió que se pudiera producir una confrontación nuclear entre ambos países pues la RPCh apenas había logrado obtener por sí misma la bomba atómica en octubre de 1964 (Tayler \& Medeiros, 2006, p.48).

15. Según el historiador chino Liu Chenshan, la Unión Soviética desistió de su intento por realizar un ataque nuclear contra la RPCh, cuando el 15 de octubre de 1969, después de los enfrentamientos fronterizos sino-soviéticos y del encuentro entre Alexei Kosiguin y Zhou Enlai, el canciller soviético hizo saber a Breshnev que el presidente Nixon había advertido que su país no se quedarían con los brazos cruzados y advirtió a Moscú que un ataque nuclear a la RPCh podría desencadenar una Tercera Guerra Mundial (Daily Telegraph, 2010). 
2003, p.71; Tyler, 1999, pp.158-159). ${ }^{16}$ Por su parte, si bien el régimen de Pekín veía al poder estadounidense como una fuerza de contrapeso, también es cierto que el propio Mao desconfiaba que Estados Unidos arriesgara su supervivencia por la RPCh en una guerra nuclear con la URss (Tyler, 1999).

En abril de 1971 la RPCh y Estados Unidos tuvieron un nuevo acercamiento luego de que funcionarios chinos invitaran a un equipo estadounidense de Ping-Pong a su país como una forma de preámbulo diplomático (Rossabi, 2014, p.391). ${ }^{17}$ Asimismo, en octubre de ese mismo año a la RPCh le fue reconocido el escaño que anteriormente ocupaba el gobierno nacionalista chino en la ONU. ${ }^{18} \mathrm{Si}$ bien es cierto que Estados Unidos siguió sin reconocer oficialmente al gobierno de Pekín, e incluso buscó que el régimen nacionalista no fuera expulsado de dicha organización internacional (Sinha, 2003, p.72), ${ }^{19}$ esos dos eventos sellaron de forma definitiva la salida del régimen chino del aislamiento al que se había confinado durante la segunda parte de la década de 1960, en especial, por la llamada Revolución Cultural. El acercamiento de Estados Unidos con China, permitió por un lado, que el gigante asiático se insertara progresivamente en el contexto internacional, al tiempo que confirmó a Estados Unidos como el líder promotor y defensor del multilateralismo en un escenario normativo e institucional, en especial, a partir de la década de 1980 (Wang, 2015, p.111). ${ }^{20}$

16. Estados Unidos consideraría cualquier amenaza a la integridad de la RPCh como incompatible con sus propios intereses y con la conservación de la paz mundial pues la viabilidad e independencia de China era un "requerimiento para la paz del mundo" (Tyler, 1999, pp.158-159).

17. A este acontecimiento se le conoció como la diplomacia del Ping-Pong (Rossabi, 2014, p.391).

18. El 25 de octubre de 1971 durante la Xxvi Asamblea General de la Organización de Naciones Unidas, por petición de Albania, se aprobó con una mayoría de 76 votos a favor, 35 en contra y 17 abstenciones, la Resolución 2758 que señalaba que la RPCh era la única representante del pueblo y Estado chino recuperando el derecho legal en ese foro (www.un.org). Asimismo, asumió su derecho legal como Miembro Permanente en el Consejo de Seguridad.

19. El gobierno estadounidense fue el opositor más importante a la resolución en lo que se refiere a la expulsión del gobierno nacionalista chino de la ONU, y su argumento se centró en que tanto la representación de la RPCh así como la de la China nacionalista fueran aceptadas por el organismo internacional, pero su propuesta fue derrotada (The Learning Network, 2011).

20. Un indicador de esta posición china es la defensa de la RPCh del papel central de Naciones Unidas en el orden internacional de la posguerra fría y la resolución de conflictos. 


\section{4) El establecimiento de la relación política sino-estadounidense durante la última década de la Guerra Fría: de Carter a Bush HW}

Christian Reus-Smit (2004), sostiene que un Estado es hegemónico no solo debido a sus capacidades materiales de poder y a su determinación de utilizarlo, sino también debido a que dicho poder se respalda en el consenso y la legitimidad al coordinar las relaciones de los diferentes países en la comunidad internacional con base en la promoción y práctica de ciertos principios y normas que el resto de los países encuentran compatibles y adaptables. En ese sentido, Pekín se había acercado a Washington con el fin de equilibrar fuerzas frente a la amenaza de invasión y ataque nuclear que percibía de Moscú tras las escaramuzas fronterizas en 1969, pues asumieron que Estados Unidos no permitiría que la URSS utilizara su arsenal nuclear impunemente en contra de China, pues iba en contra de las normas de seguridad internacional.

El 1 de enero de 1979 el gobierno del entonces presidente estadounidense, Jimmy Carter, por fin reconoció al régimen de la RPCh al tiempo que interrumpió las relaciones diplomáticas existentes entre Washington y Taiwán (Reus-Smit ,2004). Hacia esas fechas, Mao Tse-Tung había fallecido y en su lugar quedó Deng Xiaoping, un político que había sobrevivido a dos purgas y regresado a los ámbitos del poder político para dirigir a su país hacia una apertura económica estructural. De esta forma, durante la fase final de la Guerra Fría, el acercamiento político entre la RPCh y Estados Unidos afianzó la reforma económica que el gigante asiático había iniciado desde $1978 .{ }^{21}$

Deng Xiaoping tenía en claro que desde la toma del poder por parte del Partido Comunista Chino (PCCh) en octubre de 1949, China no había podido ponerse al día respecto de las economías desarrolladas. El rechazo del régimen a los mecanismos de mercado, los desequilibrios en su estructura industrial y el constante movimiento político habían afectado el crecimiento económico y social de su país (Fang, 2016, p.3). Por si fuera poco, el Gran Salto hacia Adelante y la Revolución Cultural lanzados por Mao habían terminado en un gran fracaso, lo que resultó en rezagos, así como en calamidades sociales

21. Tras la muerte de Mao Tse-Tung, la dirigencia china se trabó en una lucha interna que derivó en el ascenso de Deng Xiaoping, uno de los llamados liberales. El objetivo de Deng se centró en abrirse al comercio con el fin de darle prioridad al desarrollo económico y abatir los índices de pobreza (Chang, 1988, pp.21- 23, 42) 
y económicas que pasaron factura con la muerte por hambre de millones de personas y el desgaste del propio PCCh (Fisac \& Tsang, 2000, p.413). ${ }^{22}$

El líder chino, consciente del severo atraso económico e industrial de su país, asumió que si el PCCh deseaba mantenerse en el poder, solo podría hacerlo a través del mejoramiento en la calidad de vida de la mayor parte de la población (Goldman, 2014). Junto a otros líderes chinos, Deng Xiaoping decidió aprovechar el cambio y redirigir su trabajo hacia el desarrollo económico (Bijian, 2005: 20). Así, el nuevo gobierno retomó los objetivos que en 1964 Zhou Enlai había anunciado, en especial, las llamadas cuatro modernizaciones: agricultura, industria, ciencia y tecnología y defensa (Chow, 2004, p.128), y asumió que para alcanzarlos era necesario que su país tuviera una apertura plena al libre mercado y que procurara obtener una tecnología más avanzada (Cohen, 2010, p.224), ${ }^{23}$ por lo que supeditó el campo de lo político al desarrollo económico. De esta manera, se desplegó una reforma gradual, pasando de un fondo productivo en el sector primario a uno industrial más urbanizado (Goldman, 2014).

Por su parte, la Administración de Jimmy Carter identificó una serie de objetivos en el reconocimiento de la RPCh. En una primera instancia, Washington utilizó la enemistad entre Pekín y Moscú, así como el temor del gobierno chino a un ataque nuclear soviético como una carta a su favor, de modo que procuró establecer comunicación y colaboración geoestratégica con la RPCh frente a la URSs. De hecho, algunos consejeros en el Pentágono estaban interesados en obtener apoyo chino para combatir a la URSS, así como en coordinar acciones y traspasar información contra el régimen de Moscú

22. El régimen de Mao había limitado la economía del país a una base agrícola casi en su totalidad y su población estaba profundamente empobrecida. Por esa razón, una vez en el poder Deng Xiaoping, con el apoyo de la mayor parte de los veteranos del PCCh, comenzó a implementar la activación de granjas familiares e industria de bienes de consumo, así también involucró a su país en el comercio internacional, todo con el fin de que el PCCh conservara su mandato (Goldman, 2014).

23. La dirigencia del PCCh tenía en cuenta que la brecha económica entre China y el resto del mundo no solo no se había acortado, sino que se había ampliado, de hecho los informes gubernamentales señalan que hacia 1978 existían en China alrededor de 250 millones de personas, específicamente en las zonas rurales que vivían en el umbral de la pobreza absoluta (Fang, 2016, p.3). 
(Mann, 1998, p.80) ${ }^{24}$ La misma Casa Blanca autorizó la venta de equipo militar no letal al ejército chino, permitió acuerdos preferenciales para Pekín y envió a su Secretario de Defensa, Harold Brown a rubricar una posición común sinoestadounidense sobre la amenaza soviética que acababa de iniciar su invasión en Afganistán (Garrison, 2002, p.93). Con ello, la colaboración entre ambos países se convirtió en una de las principales respuestas de la administración Carter para hacer frente al expansionismo soviético, al tiempo que el régimen de Pekín identificó el creciente valor estratégico y político de su país para Estados Unidos frente a la Unión Soviética (Garrison, 2002).

Otro de sus intereses se centró en aprovechar la apertura implementada por el gobierno de Deng Xiaoping para involucrar a la RPCh en una amplia gama de áreas de gran interés para el gobierno estadounidense, en especial, la democratización y los derechos humanos, pero también los beneficios que podría ofrecerle el acceso a una enorme población en China (Friedberg, 2015, p.89), al tiempo que amplió las bases sociales en la relación con Pekín a través de la aceptación de estudiantes chinos en Estados Unidos y facilitó las estancias de estudiantes estadounidenses en China (Mann, 1998, p. 81). En pocas palabras, en Washington existía la creencia de que la apertura china le traería a Estados Unidos más oportunidades que retos (Bijian, 2005, p.21).

Asimismo, el entonces Secretario de Estado, Zbigniew Brzezinski argumentaba que la dirigencia china estaba muy interesada en conocer la perspectiva estadounidense del mundo y que por ello había pedido asesoría para entender dicha percepción. ${ }^{25}$ Los asesores estadounidenses buscaron impregnar a los dirigentes chinos de una visión que les permitiera inducirlos a una transformación política más liberal con respeto a los derechos humanos. Con ese fin, Washington tuvo en cuenta la necesidad de establecer un ambiente de paz y estabilidad en la región de Asia del Este y aplicó el principio

24. Tal y como Zbigniew Brzezinski, señalaba: En ese momento pudimos desarrollar una alianza casi secreta contra la Unión Soviética que involucraba operaciones conjuntas de inteligencia y asistencia a la resistencia afgana (Brzezinski \& Scowcroft, 2008, pp.116-117). En ese sentido, Joseph Frederick Bouchard señala que desde la administración Nixon con Henry Kissinger como Secretario de Estado, Washington comenzó a jugar lo que se le llamó The Chinese Card para utilizarla en su momento como contrapeso frente a la Unión Soviética (Bouchard, 1981, p.31; Hilali, 2010, p.330).

25. Washington ofreció una serie de sesiones sobre el estado de derecho, los derechos de propiedad intelectual, la economía mundial, las inversiones, el comercio internacional, las tendencias sobre tecnología militar, la democracia y las leyes, el cómo democratizar a un sistema de partido único, la relevancia de una China global y la visión general de la historia mundial con énfasis en el ascenso y caída de los poderes imperiales, lo anterior con el fin de que los líderes chinos entendieran su poder y no excedieran ciertos límites (Brzezinski \& Scowcroft, 2008, p.117). 
de Nación Más Favorecida (NMF) a China como una forma de incentivarla tanto a la apertura económica así como a la apertura política (Mann, 1998, p.107). Al mismo tiempo, le extendió la concesión de créditos del Banco de Exportación-Importación al régimen de Pekín (Mann, 1998).

Durante la década de 1980, Estados Unidos y la RPCh incrementaron su interacción política, económica y laboral. En el ámbito de la relación políticoestratégica, la acentuación de la percepción de la amenaza soviética planteó la necesidad de colaboración entre Washington y Pekín. En su objetivo de debilitar a la URSS, el entonces presidente Ronald Reagan, asumió una posición más dura frente Moscú (McCormick, 2010). En ese sentido, la Casa Blanca apoyó a la guerrilla muyahidín afgana frente a la invasión que el Ejército Rojo había comenzado en 1979 a ese país centroasiático. Por su parte, la RPCh, en pleno ejercicio de su rivalidad con la Unión Soviética, aportó información y recursos en convergencia con Estados Unidos con el fin de disminuir la influencia soviética en la región (Hilali, 2010, p.334).

En una primera instancia, Estados Unidos implementó lo que denominó Cyclone Operation (Maley, 2002, p.81), cuya financiación comenzó con la aportación de entre 30 millones de dólares en 1980, pero hacia 1986 y hasta 1989, incrementó dicho apoyo hasta alrededor de 500 millones de dólares anuales, así como asesoría militar a la guerrilla afgana (Marshall, 1998). Por su parte, la RPCh, temerosa de que el gobierno pro-soviético afgano pudiera tener repercusiones en su minoría uigur, proporcionó alrededor de 200 millones de dólares anuales a la resistencia afgana, al tiempo que acordó asistir a Estados Unidos con puestos de espionaje y vigilancia en la provincia de Xinjiang, en donde podían monitorear a los soviéticos en Asia Central (Afridi, Yousufi, \& Khan, 2014, p.2193). Asimismo, Washington y Pekín utilizaron a Paquistán como lugar de almacenamiento para el suministro de armas, municiones y dinero por medio de la Agencia Central de Inteligencia (CIA), la Inter-Service Intelligence y los servicios secretos chinos (Afridi, Yousufi, \& Khan, 2014, p. 2194).

El resultado final de la colaboración tripartita entre Washington, Pekín e Islamabad fue claro, pues la URSs fue incapaz de descifrar los accesos para detener los suministros de armas dirigidos los rebeldes afganos, y en abril de 1989 acordó retirar a sus 115 mil soldados del país centroasiático tras la firma del Acuerdo de Ginebra (De Faramiyan \& De Santayana, 2009, p.36), en una clara derrota moral y estratégica para el Kremlin. 
Desde el punto de vista económico y organizacional, en 1983 la administración del presidente Reagan, aceptó que la RPCh ocupara el puesto que anteriormente tenía Taiwán dentro del Fondo Monetario Internacional (FMI) y el Banco Mundial (BM) (Narodowski, 2017, p.283). Asimismo, Pekín solicitó al Acuerdo General de Aranceles y Comercio (GATT por sus siglas en inglés) la condición de observador con la anuencia de Washington en el inicio de un proceso de quince años para una futura adhesión a la Organización Mundial del Comercio (OMC) (Narodowski, 2017). Adicional a ello, Estados Unidos abrió su mercado a los productos chinos y facilitó la inversión extranjera directa y la asesoría organizacional e industrial a China. La relación bilateral parecía estar en un punto inmejorable pues no solo lograron construir un contrapeso efectivo frente a la Unión Soviética en Afganistán, sino que también obtuvieron un beneficio común debido al incremento constante del intercambio comercial

El final de la Guerra Fría traería contratiempos en la relación política sinoestadounidense, en especial después de los sucesos en los que el ejército chino reprendió, a comienzos del mes de junio de 1989, a millares de estudiantes que se manifestaban contra la política del gobierno central que restringía la libertad y la democracia en un episodio trágico escenificado en la Plaza de Tiananmen, en donde murieron alrededor de 10 mil personas (El País, 2017). ${ }^{26}$ El régimen de Pekín no pudo ocultar la violencia ejercida por el ejército contra los manifestantes y tuvo que lidiar con las reacciones y críticas mundiales. Para ese entonces Estados Unidos comenzó a calificar de nueva cuenta al régimen chino como un país que violaba los derechos humanos, limitaba la libertad religiosa y que además amenazaba a Taiwán (Ximbo, 2001, p.64).

26. Zhao Ziyang, Secretario del PCCh en la Provincia de Sichuan y Hu Yaobang, Presidente de la Comisión Militar Central del PCCh, influyentes funcionarios los dos, trataron de ampliar la apertura del gobierno chino; el primero buscando la privatización de algunas empresas (Naughton, 1993, p.505), el segundo rehabilitó a algunos perseguidos políticos sojuzgados durante la Revolución Cultural y buscó implementar tanto la libertad de expresión en su país, así como la libertad de prensa (Rossabi, 2014). Deng y sus colaboradores destituyeron a ambos, a quienes acusaron, especialmente a $\mathrm{Hu}$, de alentar los sentimientos burgueses y de "contaminar" con ideas y valores occidentales a los jóvenes chinos. Esta situación, la muerte del propio Hu Yaobang en abril de 1989 a causa de un infarto, y la visita a Pekín del presidente soviético Mikhail Gorbachov que había implementado una serie de reformas democráticas al interior de la URSS, contribuirían a incrementar no solo las demandas de los manifestantes en Tiananmen que exigían reformas económicas y mayores libertades políticas y de expresión, sino también radicalizaron y violentaron su posición por lo que el gobierno chino justificó la represión contra éstos (Rossabi, 2014). 
En una primera instancia, Washington aprobó sanciones económicas contra Pekín. De la misma forma, algunos miembros de la Cámara de Representantes plantearon la revocación del estatus de NMF por las violaciones a los derechos humanos en Tiannamen, sin embargo, a pesar de las críticas de la Casa Blanca y de la Cámara de Representantes, el presidente George W.H. Bush envió al entonces Secretario de Estado Brent Scowcroft y al Subsecretario de Estado Lawrence S. Eagleburger a Pekín en julio de 1989, y justificó su misión con el fin de mantener vínculos estratégicos bajo los argumentos de que China tenía más de mil millones de personas y que su posición estratégica en el mundo era muy importante para Estados Unidos; por ello no se le debía aislar (Devroy \& Hoffman, 1989).

Asimismo, una mayoría en el Congreso tomó la decisión de no revocar el estatuto de NMF pues se asumía que retirar dichas ventajas comerciales para China solo fortalecería a los grupos conservadores del PCCh y que ello podría recrudecer las violaciones a los derechos humanos de la población china en general y perjudicar a grandes segmentos de la comunidad empresarial estadounidense. $^{27}$

\section{5) La relación política sino-estadounidense después del fin de la Guerra Fría: de Clinton a Trump}

George HW Bush duraría una sola administración, no obstante, fue durante su gestión que oficialmente terminó la Guerra Fría y que la Unión Soviética se desintegró a finales de 1991. Para 1993, el demócrata Bill Clinton arribó al poder. En su gobierno, Clinton asumió como una de sus banderas la ampliación de la democracia y con ello, la ampliación de los derechos humanos, por lo que tuvo algunos desencuentros con el régimen de Pekín al que acusaba constantemente de violarlos. Incluso, el nuevo inquilino de la Casa Blanca, criticó a su antecesor por la falta de acciones y sanciones efectivas contra la RPCh por los eventos en Tiannamen (Ray, 2008, pp.307-308), y por haberle renovado el trato de NMF. Por estas razones, Clinton amenazó con utilizar sanciones comerciales e intentó vincular el estatus de NMF de China con la mejoría de los derechos humanos al interior del gigante asiático (Fairbank \& Goldman, 2006, p.431). Sin embargo, el régimen de Pekín no mostró interés ni mejoría en seguir la demanda de la Casa Blanca, asimismo, en mayo de 1994,

27. United States. Congress. Senate. Committee on Finance, 1991, p.127. 
la administración de Clinton desvinculó las cuestiones de derechos humanos al estatus de NMF (Wang, 2013, p.7). ${ }^{28}$

Tras este episodio, el presidente Clinton, asumió la necesidad de desplegar una política de compromiso constructivo con la RPCh, de modo que pugnó por el fortalecimiento de los lazos políticos y económicos con el gigante asiático, al tiempo que intentó influenciar a los líderes chinos para implementar medidas de una mayor apertura y el respeto a los derechos humanos; su planteamiento se centró en que, a final de cuentas, cualquier intento de aislamiento hacia China sería contraproducente y peligroso (Ray, 2008, p.308).

La ambivalencia del gobierno de Clinton respecto de la RPCh en materia política y económica desarrolló una dinámica dicotómica entre ambos países. Por un lado, Clinton y los empresarios estadounidenses entendían la relevancia de grandes ganancias en el crecimiento de su comercio con China, tanto por su mano de obra barata, así como por el potencial como mercado en un país que en ese momento contaba con alrededor de 1,300 millones de habitantes, pero por el otro lado, las elecciones en Taiwán en donde se presentaba un posible triunfo de los independentistas, provocó maniobras militares del ejército chino frente a dicha isla y con ello Washington justificó la renovación de su alianza militar con Japón (McCormick, 2010, p.186), lo que produjo nuevos motivos de desconfianza mutua.

A pesar de la tensión producida por la nueva crisis en el estrecho de Taiwán, ambos gobiernos tuvieron una nueva oportunidad de cooperar para mantener la estabilidad en la Península de Corea cuando ante la persistencia del gobierno de Corea del Norte de avanzar en su programa nuclear tendiente a conseguir armamento de destrucción masiva puso en alerta máxima a Estados Unidos, y ante la imposibilidad de lograr disuadir efectivamente al líder norcoreano Kim Jong-il de continuar con dicho programa, tuvo que pedir apoyo a la RPCh, el país con más influencia hacia el régimen de Pyongyang. El papel diplomático chino fue determinante para detener, en ese momento, el programa nuclear norcoreano a través de la promoción de las pláticas de las cuatro partes. ${ }^{29}$ Como resultado relevante de este episodio, Washington tuvo

28. Si bien es cierto que Bill Clinton pasó por alto al Congreso y emitió la Orden Ejecutiva 128590 que vinculaba la renovación del estatus de NMF de China a siete condiciones relacionadas con cuestiones de derechos humanos en mayo de 1993, un año después revirtió su postura. (United States. Congress. Senate. Committee on Finance, 1991, p.127).

29. Se le llamaron Pláticas de las Cuatro Partes porque participaron las representaciones diplomáticas de Estados Unidos, la RPCh, la República de Corea y la República Popular Democrática de Corea. 
que reconocer a China como un actor de enorme relevancia en los asuntos de seguridad en Asia del Este, asimismo dio vía libre a la membresía de China en la Organización Mundial del Comercio (OMC) (González, 2002, p.15).

El inicio del siglo XXI marcó un nuevo episodio de la relación sino-estadounidense con el ascenso del republicano George W. Bush a la Casa Blanca. El nuevo presidente coincidía con su antecesor respecto a las premisas de la política exterior de Estados Unidos hacia la RPCh. Lo primero era motivar la expansión del comercio y la inversión extranjera en China para producir más riqueza, y que una China rica tuviera más probabilidades de convertirse a la democracia en un ambiente estable y democrático dirigido por Estados Unidos (Ray, 2008, p.309). Sin embargo, el incidente del avión espía estadunidense en la isla de Hainan que requisaron las autoridades chinas y la venta de armas estadounidenses de última tecnología a Taiwán (Ou, 2011, p.104), produjeron nuevos desencuentros entre ambos países.

Con respecto a la lucha contra el terrorismo promovida por el presidente W. Bush, la RPCh apoyó a Estados Unidos cuanto inició represalias contra el régimen talibán en Afganistán, no obstante, rechazó la invasión estadounidense emprendida contra Irak por considerarla unilateralista y fuera de los compromisos institucionales internacionales, al tiempo que comenzó a enfatizar junto a Rusia, en la necesidad de un mundo multipolar, una demanda que había hecho desde la década de 1990 (Federation of American Scientists [FAS], 1997), ${ }^{30}$ en especial porque comenzó a identificar la política desplegada por Washington como amenazante para sus intereses $y$, por ende, para su seguridad nacional. ${ }^{31}$

En 2009 llegó a la Casa Blanca el demócrata Barack Obama. El nuevo presidente señaló la relevancia de recuperar la influencia de Estados Unidos y armonizar las relaciones con aquellos países con los que su antecesor tuvo problemas, en esa sintonía, se enfocó en resaltar la corresponsabilidad en temas de seguridad, es decir, en la práctica multilateralista. Sin embargo, Obama empezaría una relación tensa al plantear una dura crítica al gobierno

30. China, Russia sign pact: Oppose any single world power. (CNN, 1997). Recuperado de http:// edition.cnn.com/WORLD/9704/23/russia.china/

31. Las declaraciones del presidente George W. Bush sobre la existencia de "Estados canallas" que conformaban un "Eje del Mal" -Irak, Irán y Corea del Norte- fueron percibidas por parte de Pekín como amenazas hacia algunos intereses centrales chinos, pues Irán es uno de los mayores proveedores de petróleo y Corea del Norte es considerado como central en la seguridad periférica china. 
de Pekín, al que acusó de indiferente al respeto a los derechos humanos de la minoría uigur durante la crisis de Xinjiang en 2009.

No obstante, Obama sostenía que el asunto de los derechos humanos no definía las relaciones con la RPCh y que su país no pugnaba por contener la pujanza del crecimiento chino (The White House, 2014). En todo caso, Estados Unidos promovía la participación igualitaria en "la mesa" porque de esa forma la propia China tendría más probabilidades de estar de acuerdo con el orden mundial prevaleciente (Freund \& Martey, 2017, p.11).

Sin embargo, durante una visita a Australia en 2011, Obama señaló que el futuro de su país estaba en la región Asia-Pacífico y la defensa de sus principios fundamentales se realizaría en una estrecha colaboración con sus aliados (De Swielande, 2012, p.75). Asimismo, Estados Unidos desplegó una nueva estrategia para conservar la directriz de la economía mundial asumiendo el liderazgo del Acuerdo Transpacífico de Cooperación Económica (TPP por sus siglas en inglés). Este acuerdo de libre comercio que incluía a otras 11 economías de Asia, Oceanía y América, y se proyectaba como un mecanismo estratégico con fines geopolíticos dirigido a consolidar la posición hegemónica de Estados Unidos ante la imparable embestida del creciente poder económico, político y militar chino en la región Asia-Pacífico (Lo, 2018, p.94).

Sin embargo, el nuevo presidente estadounidense Donald Trump, al auspicio de la idea dominante "America First" abortó la estrategia geopolítica de su antecesor, pues desde su campaña acusó a la RPCh de realizar prácticas de comercio desleal, lo que en palabras de Trump explicaba el enorme déficit comercial que hacia 2016 rondaba los 347 mil millones de dólares (Pace, 2017), y que se proyectaba aumentar con cerca de 500,000 millones de dólares hacia 2019, de modo que prometió una guerra comercial sin cuartel contra el gigante asiático. Una vez en la presidencia, Trump empezó a materializar sus promesas electorales. De esta forma, 23 de enero, apenas tres días después de haber llegado a la Casa Blanca, el nuevo presidente sacó a Estados Unidos del TPP (BBCMundo, 2017). Con ello Trump detuvo un proyecto geopolítico de gran interés para sus antecesores, cuyo fin era el de regular el comercio con normas específicas, garantizar una mayor presencia de su país en la región Asia-Pacífico y con ello contrarrestar la influencia creciente de China en esa zona.

Consecuente con su discurso "America First", Trump implementó a mediados de 2017 "la prometida" guerra comercial contra la RPCh centrada en la aplicación de aranceles de hasta un 25\% a alrededor de 1,300 productos chinos, bajo el argumento de que el déficit comercial de su país con China 
ya alcanzaba 500 mil millones de dólares al año, y con el robo de propiedad intelectual, implicaba además, ya en ese momento, el déficit de otros $300 \mathrm{mil}$ millones de dólares (El Economista, 2018). En respuesta, China impuso tarifas arancelarias espejo a productos agrícolas estadounidenses, tales como la soya y el maíz; a productos químicos, aviones y artículos de plástico (El Economista, 2018). En esa sintonía, con el ascenso de Trump, las divergencias entre ambos países han crecido de nueva cuenta.

\section{6) Del conflicto a la convergencia: una visión constructivista}

Como ya se señaló anteriormente, el constructivismo no solo nos ofrece una alternativa explicativa sobre la relevancia de las identidades de los Estados y de cómo su comportamiento puede modificarse a partir de la aceptación de normas que encuentra estratégicamente relevantes para sus intereses centrales, es decir, para sus metas y objetivos más importantes.

En un primer momento, con el surgimiento de la Guerra Fría, Estados Unidos asumió como una enorme pérdida el triunfo de los comunistas en China (Powaski, 2014, pp.102-105), y la inclinación china hacia la URSS (Gaddis, 2011, p.57). Asimismo, hubo una gran preocupación capitalizada en 1950 por la intromisión militar sino-soviética en la Guerra de Corea.

La preocupación de Estados Unidos en ese momento era clara, con base en su autopercepción identitaria como potencia hegemónica, asumió que su seguridad nacional y la del orden internacional que estaba promoviendo, se encontraban en peligro, por lo que desde 1947 implementó una política de contención al comunismo en cualquier parte del mundo que esta ideología retara su dominio, ${ }^{32}$ asimismo, entendió que necesitaba poner especial atención en lo que estaba pasando en Asia del Este.

Por su parte, los líderes chinos asumían que su pueblo tenía una experiencia histórica traumática debido a la intromisión extranjera -tanto europea como japonesa- desde mediados del siglo XIX, por esta razón durante la Guerra de Corea, conscientes de la hostilidad declarada de Washington hacia su régimen y del acercamiento de las tropas occidentales en la frontera del

32. Tras el envío del famoso telegrama de George Kennan (1947), el entonces asesor en la Embajada de Estados Unidos en Moscú, señalaba la necesidad de que el gobierno de su país desplegara una política destinada a contener a la URSS o cualquier otra amenaza al orden favorable a los intereses estadounidenses, en cualquier parte del mundo y a través de diversos medios. Este planteamiento dio origen a la famosa Doctrina de Contención o Doctrina Truman. 
río Yalú, percibieron una clara amenaza a su seguridad nacional (Jian 1994, p.127), y en ese momento identificaron el asunto de Corea como el problema internacional más importante de expresión imperialista estadounidense y de mayor amenaza para el nuevo régimen y su lucha por una China unificada (Jian 1994, pp.127-150).

El gobierno de Pekín ordenó el envío deliberado de cientos de miles de soldados del ELP a la guerra coreana como respuesta a lo que percibieron como amenaza militar extranjera y, por lo mismo, en respaldo al régimen de Kim Il-sung, el hombre que había iniciado el conflicto. ${ }^{33}$ Con ello se identificó a la RPCh como un Estado que amenazaba una Resolución promovida y aceptada por una mayoría en el Consejo de Seguridad de Naciones Unidas y que, por ende, atacaba a las normas consensuadas por la Sociedad Internacional. Asimismo, el alto al fuego negociado a mediados de 1953 no significó un fin de las hostilidades entre la RPCh y Estados Unidos, de hecho, Washington continuó el apoyo para que el régimen de la República de China, estacionado en la isla de Taiwán, siguiera representando ante la ONU, al pueblo y Estado chino, y con ello bloqueó cualquier iniciativa para que la representación de Pekín fuera reconocida por este organismo internacional.

Durante la década de 1950, uno de los rectores de la identidad del nuevo régimen en Pekín fue el de la integridad territorial china y para ello era necesario recobrar aquellos territorios que los chinos identificaban como suyos, de modo que Taiwán recuperó su atención. En esa sintonía, la amenaza de ataque chino a dicho territorio durante la crisis de 1958 y la respuesta estadounidense que incluso motivó una serie de advertencias soviéticas a Washington y a Pekín -por separado-, le costaron a la RPCh el inicio de una doble confrontación, pues ahora no solo estaba enemistada con Estados Unidos, sino que también comenzó a distanciarse de la URSS, pues rechazaba las llamadas de atención soviéticas debido a que la RPCh asumía que sus intereses eran claros y explícitamente propios, por lo que ni siquiera el país al

33. La RPCh envió inicialmente alrededor de 300,000 hombres a la Guerra de Corea porque identificó la intromisión de los estadounidenses como una amenaza directa a su régimen, asimismo, los denominó como "El Ejército Voluntarios del Pueblo Chino", debido a que pretendía mostrarse ante el mundo como un país que no se estaba involucrando directamente en dicha guerra y para evitar la justificación de un ataque estadounidense contra China (Gaddis, 2011, p.64). Por su parte, la Unión Soviética respaldó la defensa sino-norcoreana en 1951 con el envío de varios escuadrones aéreos de Mig15 bajo la bandera norcoreana, lo que permitió equilibrar los combates aéreos en la península (Krylov \& Tepsurkaev, 2008, p.2). 
que reconocía como líder de la revolución socialista mundial debía interferir o criticar lo que consideraban como un derecho legítimo; el de su integridad territorial. ${ }^{34}$ Posteriormente, la obtención de la bomba atómica en 1964 y la Revolución Cultural sentenció a la RPCh al aislamiento mundial durante la mayor parte de la década de 1960.

La percepción de una China amenazante por parte de Estados Unidos durante la década de 1960 se fue alimentando con el desarrollo de las acciones del régimen chino tales como la guerra contra la India en 1962, la posesión del arma atómica en 1964, así como el fracaso económico del Gran Salto hacia Adelante y las persecuciones del gobierno de Mao contra algunos partidarios del PCCh en lo que se conoció como la Revolución Cultural al interior de China. De hecho, la administración del entonces presidente estadounidense Lyndon B. Johnson, señaló que la RPCh era una potencia agresiva y expansionista impulsada por su propio fermento revolucionario, y que dicho expansionismo se derivaba de la certeza del gobierno de Mao sobre el triunfo final del socialismo revolucionario (Garson, 1997, p.68-70). Con ello la imagen de una China comunista con un régimen represor al interior y que rechazaba la normatividad internacional continuó.

Sin embargo, el recrudecimiento de los enfrentamientos fronterizos sinosoviéticos en 1969, planteó la posibilidad de que Estados Unidos comenzara a pensar en sacar provecho de China en su contención contra la Unión Soviética bajo un claro planteamiento que identifica al realismo: "el enemigo de mi enemigo es mi amigo". Sin embargo, el acercamiento sino-estadounidense tiene una explicación mucho más amplia que un razonamiento explícitamente realista. En una primera instancia, el poder soviético en sí, no solo era visto por Estados Unidos y la RPCh como una amenaza desde el punto de vista militar y político, sino también desde el punto de vista identitario, pues en el caso de Estados Unidos, consideraba a la URSS como un peligro respecto a sus valores y el orden internacional que dirigía y que pretendía preservar, mientras que la $\mathrm{RPCh}$ ahora la identificaba como una nueva amenaza ideológico-imperialista que ambicionaba someterla, pero con la percepción de un mayor peligro dada la enorme frontera terrestre que compartían.

34. El régimen de Mao Tse-Tung ya había criticado duramente la política lanzada en 1955 por el entonces líder de la Unión Soviética Nikita Khrushchev, que planteaba la disminución de la tensión Este-Oeste (Lightbody, 1999, p.36). 
Para Estados Unidos y la RPCh estaba claro que la URSs era su enemigo y que tratarían de aprovechar el juego del equilibrio estratégico colaborando entre ellos. Asimismo, la amenaza soviética de utilizar sus misiles nucleares contra China para terminar el conflicto fronterizo, así como su reciente invasión a Checoslovaquia en 1968, habían producido en Pekín una percepción de peligro. En ese sentido, Henry Nau (2002), señala que la identidad de un Estado, define qué es aquello que lo amenaza y qué es lo que lo beneficia, al tiempo que identifica cuáles son sus intereses centrales. En ese contexto, tanto para Estados Unidos, así como para la RPCh, la URSS era considerada como una potencia imperialista de tipo ideológico y como un actor que amenazaba con quebrar la base normativa y poner en peligro a todo el mundo a través del uso de armas nucleares contra un país como China, que no tendría la misma capacidad de responder, ${ }^{35}$ con el peligro de producir con ello, un antecedente catastrófico.

De esta forma, Estados Unidos, de acuerdo con sus principios, se acercó a la RPCh y le ofreció beneficios políticos y económicos como su nuevo "socio" estratégico por lo que le otorgó dos cosas que el régimen de Pekín deseaba: su reconocimiento diplomático y la apertura de su mercado, ambas como herramientas para motivar a China la práctica de patrones en la estructura normativa creada y promovida por Estados Unidos. Por su parte, el gobierno de la RPCh aceptó esta oferta con dos atenuantes coyunturales favorables, su reconocimiento en la ONU como único representante del pueblo y Estado chino en 1971 y la reforma que el nuevo líder chino, Deng Xiaoping, implementó en 1978.

Según Clark (2014), las normas reflejan el poder de los países dominantes al socializar sus valores y patrones de comportamiento, o como señala Checkel (1998), funcionan como reguladores de la actuación de los Estados en el escenario internacional. Por esa razón, para Estados Unidos el reconocimiento del gobierno de Pekín como auténtico representante del pueblo y Estado

35. Richard Ned Lebow, (2001), señala en referencia a la explicación constructivista que da sobre la Guerra del Peloponeso que los atenienses habían violado normas y aquello que Tucidides llamó "honorabilidad", lo cual era una serie de prácticas que demandaban igualdad y ciertos principios de la regulación de relaciones en lo que se conoció como el mundo helénico. En este caso, los soviéticos planteaban el rompimiento de cierta concordia atacando la soberanía checoslovaca, amenazando con lanzar armas nucleares -aunque fuera a sus instalaciones nucleares- a un país que no tenía la misma capacidad de responder, una situación que además asentaba un precedente peligroso sobre la posibilidad de utilizar este tipo de armamento en cualquier otro conflicto. 
chino tuvo como objeto no solo equilibrar las fuerzas en Asia Central frente a la URSS y detener cualquier embestida militar del Kremlin, ahora también deseaba involucrar y comprometer al régimen comunista chino a aceptar las normas que Washington promovía para tratar de modificar una conducta revolucionara considerada como peligrosa.

Por su parte, el régimen chino aceptó la estructura normativa liderada por los estadounidenses y renunció expandir dicha perspectiva revolucionaria porque identificó que las normas propuestas por Washington eran relevantes para sus propios fines y le proporcionaban algunos beneficios tanto materiales como sociales; es decir, como un actor confiable porque respetaba las normas que la mayoría de los Estados habían aceptado.

La colaboración sino-estadounidense para contener el poder soviético continuó durante la década de 1980 con el apoyo que ambos países proporcionaron a los guerrilleros muyahidines en Afganistán; no obstante, como ya se señaló antes, la relación económico-comercial fue el espacio en donde ambos pudieron encontrar una mayor colaboración, pues para Pekín, este entorno representó la oportunidad de crecimiento y desarrollo, mientras que para Washington significó una estrategia para continuar influenciando al gigante asiático frente a la URSS y para persuadirlo de que adoptara una política de apertura que lo llevara al ejercicio de la democracia. Con ello, buscó que la RPCh no volviera a significar una amenaza a su seguridad. Al mismo tiempo, ambos obtuvieron beneficios con base en una interacción que producía confianza mutua.

\section{7) Posguerra Fría y siglo xxI: la aparición de nuevas divergencias}

El fin de la Guerra Fría y la caída de la URSS significaron la aparición de un nuevo escenario en donde ya no existía la amenaza común soviética y, por ende, ya no había motivos político-estratégicos para continuar cooperando. Sin embargo, el aumento del comercio entre Washington y Pekín, así como el incremento incesante de los flujos del comercio en la región Asia-Pacífico, en donde Estados Unidos y la RPCh comparten un espacio común, planteó una mixtura de características en la relación bilateral, pues sus intereses podrían coincidir, en específico, respecto a ciertas normas y reglas internacionales o divergir en lo que se refiere a los intereses de integridad territorial por parte de la RPCh y a la preservación del statu quo y la credibilidad en sus capacidades de poder y 
sus compromisos internacionales por parte de Estados Unidos, no obstante, Washington parecía tener éxito en la promoción de normas hacia Pekín.

En una primera instancia, había logrado que el régimen chino tomara nuevas decisiones y se adhiriera a la práctica del libre comercio, renunciara a la expansión del comunismo y aportara firmeza respecto a la conservación de un statu quo estable y favorable, y si bien es cierto que los eventos de Tiannamen en 1989 habían producido diferencias entre los dos gobiernos respecto al tema de los derechos humanos al interior de China, también lo es, el hecho de que no determinó las condiciones de la relación bilateral. A su vez, la RPCh aseguró ganancias claras como el reconocimiento de que Taiwán es parte de su soberanía y el regreso de Hong Kong bajo el compromiso con Reino Unido de poner en práctica el principio de un Estado dos sistemas, al menos hasta $2047 .{ }^{36}$

El aumento del comercio bilateral también permitió a la RPCh colocarse como la principal potencia emergente a finales de la década 1990 y hacia 2011 se posicionó como la segunda potencia económica mundial por encima de Japón (BBCNews, 2011). En pocas palabras, la irrupción china en el comercio internacional replanteó patrones y directrices del comercio mundial (Cafruny, 2019, p.103). Asimismo con el fin de contrarrestar el temor de que la emergencia china representara una amenaza, en 2003, los líderes chinos articularon una política denominada "Ascenso o Desarrollo Pacífico". Incluso en 2004, el entonces Primer Ministro, Wen Jinbao, señaló que el ascenso de su país no se produciría a costa de ningún otro Estado o supondría una amenaza para nadie, y que China nunca buscaría la hegemonía (CNN.China, 2004). En todo caso, China buscaría promover una imagen benigna y pacífica de sí misma mostrándose ante el mundo como una potencia respetuosa de las normas internacionales (Han, 2017, p.282). ${ }^{37}$

$\mathrm{El}$ incremento de sus capacidades económicas, sus enlaces comerciales y las nuevas demandas territoriales, así como el acercamiento a Rusia han puesto a China en un nuevo contexto en el que confirma su rechazo al orden

36. En la misma situación se encuentra Macao que fue reivindicado a China por Portugal en 1999.

37. Las principales normas internacionales que la RPCh demanda a respetar y que plantea como centrales son las referentes al libre comercio y el desarrollo, la no intervención, la soberanía y la integridad territorial (Zhou, 2019, p.33). 
unipolar protagonizado por el poder estadounidense. ${ }^{38}$ Asimismo, en 2013, el nuevo presidente chino, Xi Jinping, lanzó un enorme proyecto destinado a implementar inversiones de infraestructura para el comercio que abarca diferentes naciones en Eurasia y África, tomando como referencia la antigua ruta de la seda (Sarker, Hossin, Yin, \& Sarkar, 2018, p.624), lo anterior con el objetivo de hacer posible el denominado "sueño Chino" (Müller-Markus, 2016, p.1). A lo anterior se suma un notable incremento en el presupuesto de defensa chino del 5\% en 2018, alcanzando la cifra de 250,000 millones de dólares (Stockholm International Peace Research Institute [SIPRI], 2018). ${ }^{39}$

Ante este escenario, y en su identidad como potencia guía del orden internacional, Estados Unidos ha remarcado su percepción sobre una China retadora de su statu quo. Esta situación se ha acentuado con el incremento incesante del superávit comercial chino con respecto a Estados Unidos que en 2017 alcanzó más de 375 mil millones de dólares. Asimismo, la cuarta parte del total de letras del tesoro, notas y bonos estadounidenses en poder de países extranjeros, están en manos de Pekín (Bichara, 2017). ${ }^{40}$ Por si fuera poco, varios de los principales aliados de Estados Unidos tienen ahora como su principal socio comercial precisamente a China (Leverett \& Bingbing, 2017,

38. En 1997 China y Rusia firmaron una declaración política en la que si bien no se pronunciaba el nombre de Estados Unidos, se manifestaron contra un mundo unipolar dirigido por la única superpotencia en ese momento (El País, 1997). Ambos países continúan en esa directriz, además firmaron el Pacto de Shanghai (Organization Shanghai Cooperations (ocs) que entró en vigor en 2003 y entre cuyos fines está rechazar la intromisión de un ejército de un tercer país en el territorio de cualquiera de los ocho miembros de la ocs. Asimismo, China, Rusia y otros países miembros del ocs han estado realizando ejercicio militares conjuntos desde hace algunos años (Rabena, 2018).

39. En 2013 el Ministerio de Defensa Nacional de la RPCh señaló que el crecimiento del país le plantea nuevos retos que respondan a sus intereses nacionales y que por ello debe de asumir una postura estratégica favorable por lo que se debe de invertir en su defensa para estar seguro y fuerte, de hecho, desde ese año el gobierno chino ha asignado 1.9 \% de su Producto Interno Bruto (PIB) a este rubro (China's Ministry of National Defense, 2013).

40. Esta situación le otorga cierta capacidad de presión a China, ya que posee el poder de influir en el incremento de las tasas de interés estadounidenses y afectar con ello su crecimiento y la fortaleza del dólar. Asimismo, la deuda de Estados Unidos con China es de más de 1 millón de millones de dólares, lo que representa el $27.8 \%$ del total de la deuda estadounidense emitida en bonos, notas y letras del tesoro. En una primera instancia, los dos países parecen salir ganando con esta transacción, ya que por un lado, China mantiene su moneda más débil que el dólar y ello la hace más competitiva al mantener sus exportaciones más baratas. Por su parte, con la venta de activos de su deuda a Pekín, el gobierno federal estadounidense puede implementar programas con bajas tasas de interés lo que le permite mantener un crecimiento constante de la economía doméstica; la desventaja es que con ello, Washington asume que ya no tiene un pleno dominio de su propio crecimiento económico (Bichara, 2017). 
p.117), lo que en suma produce una gran incertidumbre en Washington, no solo respecto al crecimiento de la economía china, sino también a la intención de sus intereses que ahora compiten en aquellos espacios en dónde antes el dominio económico estadounidense era casi absoluto.

Por esta razón, desde 2011, con la declaración del entonces presidente Barack Obama acerca de que Asia es una prioridad para Estados Unidos, ${ }^{41}$ así como de la idea de poner en funcionamiento el TPP durante su gestión y posteriormente con el abandono de este proyecto y la guerra comercial implementada por el actual presidente Donald Trump, que a través de sanciones ha intentado contener el crecimiento chino, deja en claro que Estados Unidos se rehúsa a que el statu quo pueda ser modificado por la irrupción de una China poderosa e influyente, incluso, si este nuevo objetivo plantea el rechazo del actual gobierno en Washington de valores tradicionales estadounidenses como el libre comercio. ${ }^{42}$

Los líderes chinos por su parte, identifican las acciones estadounidenses, en especial, las de los dos últimos presidentes, no solo como un freno a su crecimiento económico, sino también como una contención a sus intereses centrales. En ese sentido, desde el ascenso de Xi Jinping, su administración ha declarado que la RPCh tiene como objetivo buscar un ambiente pacífico para desarrollarse y que ningún país debería esperar a que China cambie dichos intereses centrales: soberanía, seguridad y desarrollo, los cuales son la base de su interacción normativa (Zhou, 2019, p.33). Desde su reconocimiento por parte de la ONU en 1971 y el reconocimiento por parte de Estados Unidos en 1979, la RPCh se ha insertado como un actor importante en la normatividad del orden internacional creado por Estados Unidos. En ese sentido, China desea mantener las condiciones de estabilidad actual para continuar con su crecimiento, pues la estructura normativa actual le ha favorecido.

Asimismo, la reforma implementada por el régimen de Pekín en 1978, así como la apertura de los mercados estadounidenses, que a su vez colaboraron en la recepción de muchos otros mercados y créditos de las instituciones bancarias internacionales, han permitido alcanzar algunas metas centrales. En primer lugar ha fortalecido la existencia de China y del propio PCCh pues gracias al comercio, ha logrado sacar de la pobreza extrema a más de 800 millones

41. (Obama, 2011) Remarks By President Obama to the Australian Parliament.

42. El proteccionismo comercial del presidente Trump y su disposición a rechazar las normas de la OMC no solo han sido dirigidos contra la RPCh, sino también contra México, Rusia y la Unión Europea. 
de personas (Banco Mundial, 2016). Además, el continuo crecimiento de su economía ha permitido que la RPCh pueda desarrollar grandes industrias e implementar inversión en tecnología, así como algunos de sus objetivos sobre su integridad territorial. ${ }^{43}$ En pocas palabras, los logros conseguidos por el gobierno chino en los últimos cuarenta años han ayudado al PCCh a legitimar su estancia en el poder, sin importar si es considerado democrático o no.

Los líderes chinos reconocen que las normas e instituciones internacionales han proporcionado una plataforma para el desarrollo de la RPCh, en ese contexto, Pekín ha procurado desempeñar un papel efectivo en lo que se refiere al fortalecimiento de la estabilidad regional. En su papel de potencia emergente, China ha comenzado poner mayor atención en asuntos de interés mundial como la lucha contra el cambio climático y ha optado por el orden económico liberal prevaleciente (Xuetong, 2019, p.44).

Sin embargo, la magnitud del poder chino y sus planes de expandir sus estrategias comerciales, demandan el respeto a sus intereses centrales y, en ese sentido, se asoma la posibilidad de reclamar el cambio de las normas dominantes en el sistema internacional (Han, 2017, p.275). Ante ese contexto, la percepción estadounidense del crecimiento chino como amenaza se afianza, y el escenario internacional es observado con incertidumbre ante la posibilidad de cambios (De Graaff y Van Apeldoorn, 2018, p.127), en especial, con una Administración Trump empecinada en una guerra comercial con la RPCh, pero alejada de las responsabilidades que Estados Unidos ha desarrollado tradicionalmente como potencia hegemónica, cuestionando con ello dicha posición en un momento en el que la $\mathrm{RPCh}$, con sus proyectos, se convierte en una nueva opción de comercio y desarrollo para el resto de los miembros de la comunidad internacional, una situación que puede proponer la implementación de nuevas normas en el orden internacional.

\section{8) Conclusiones}

La pregunta planteada al inicio de este artículo y que sirvió como inductor analítico, obligó a indagar y a tratar de construir una respuesta sustentada tanto en la relevancia de los beneficios materiales y estratégicos, así como en la aceptación, por parte de China, de un orden normativo estadounidense

43. Qin Gang, portavoz del Ministerio de Asuntos Exteriores de la RPCh, señala que el crecimiento en el presupuesto militar chino está acorde a su desarrollo económico (Tiezzi, 2014). 
destinado a influir para realizar cambios sustanciales en su andamiaje doméstico. La respuesta a la pregunta tiene que considerar en que es posible que no exista una relación política más compleja y de mayor relevancia global que la que hay entre Estados Unidos y China, pues en una dinámica de convergencias y divergencias son las dos principales potencias económicas del mundo, así como socios comerciales de alto nivel. En una primera instancia, el acercamiento entre ambos países durante la década de 1970 se dio no solo bajo la idea de que el enemigo de mi enemigo es mi amigo, en un escenario en el que la Unión Soviética representaba la mayor amenaza a la seguridad de ambos países, sino porque el proyecto soviético ya no era atractivo a la perspectiva y las necesidades de China. De la misma forma, en 1979, una vez formalizada dicha relación, Washington persuadió a China a integrarse al orden normativo global liberal que lideraba con el fin de que el régimen comunista introdujera reformas democráticas internas y renunciara a expandir el comunismo, en un mundo bipolar que duraría hasta 1989.

Por su parte, en un ambiente de convergencias con Washington, el régimen de la RPCh se sirvió de la economía estadounidense como el principal destino de sus productos y una fuente esencial de estímulos tecnológicos y académicos, como una vía para la obtención de créditos bancarios e instituciones internacionales (Leverett \& Bingbing, 2017, pp.123-123). En breve, China aceptó a Estados Unidos como el guía de la modernización que le propiciaría su desarrollo económico. Por ese motivo, una vez terminada la Guerra Fría y desintegrada la Unión Soviética, lejos de retar el orden normativo prevaleciente (Bijian, 2005, p.22), mantuvo su reconocimiento a Estados Unidos como potencia hegemónica y desistió de buscar el liderazgo del movimiento comunista (Chen, 1995, p.5).

De esta manera, China se pudo insertar en la estructura normativa de libre mercado que promovió Estados Unidos y, a partir de ahí, ha sacado provecho al máximo expandiendo su comercio y su presencia alrededor del mundo, al grado de convertirse en la segunda potencia económica en la primera mitad del siglo Xxi. No obstante, el crecimiento incesante de su economía también la ha transformado en un competidor directo por mercados y materias primas con Estados Unidos, así como en el país con el que Washington tiene el déficit comercial más grande y el principal comprador de bonos de deuda estadounidense.

Ahora bien, la hipótesis propuesta al principio del artículo y que fungió como eje conductor, resulta ser consistente, pues si bien es cierto que Wash- 
ington pudo incorporar al régimen chino su orden internacional a través de su reconocimiento en 1979 y de su inserción en una dinámica de libre comercio con los objetivos de persuadir a China de ser una amenaza para dicho orden y de abrirse a la democracia, fracasó en este último, pues Pekín no se ha democratizado, pues los líderes chinos estiman que lejos de afectarlo, el orden internacional prevaleciente les ha resultado benéfico en sus objetivos por modernizar a su país y disminuir la pobreza extrema, lo que ha llevado a legitimar al PCCh, por esa razón no tienen incentivos para introducir reformas democráticas.

Con respecto a su tránsito en el orden internacional, los logros del PCCh han permitido a China adoptar nuevos valores como el libre comercio, al tiempo que ha remarcado los ejes identitarios fundamentales que asumió desde la misma fundación de la RPCh, es decir, el respeto a la soberanía, a la integridad territorial y la no intervención. No obstante, el régimen de Pekín tiene presente dos situaciones actuales a considerar: primero, que la magnitud del crecimiento económico de su país ha producido la percepción de una China amenazadora y que ha dañado su imagen, lo que podría limitar la eficacia de su política exterior, de ahí su discurso sobre el ascenso pacífico. En segunda instancia, China se está convirtiendo en una gran potencia en un orden normativo que no es de su creación (Clark, 2014, p.318), no obstante, desea la existencia de una estructura normativa estable y pacífica que le permita no solo mantener un crecimiento continuo, sino que además, no limite el dinamismo de su crecimiento. De ahí el interés nacional chino de promover e implementar una estrategia de expansión global de su comercio a través de un proyecto como el Belt and Road Iniciative (BRI), que contempla la inversión de cientos de miles de millones de dólares en infraestructura con el fin de "revivir" la vieja ruta de la seda. A dicho proyecto ya se han sumado algunos países de Europa, Asia, África y América Latina.

En breve, hasta hoy en día, el orden dirigido por Washington ha sido satisfactorio para la meta de modernización china y, tanto Estados Unidos como la RPCh han mantenido una dinámica estable y relativamente pacífica a pesar de sus divergencias, no obstante, con el BRI la RPCh puede pretender replantear dicho orden normativo. Como respuesta al crecimiento chino y a su competitividad, en 2017 el actual presidente estadounidense, Donald 
Trump, señaló a China como competidor estratégico, ${ }^{44}$ y bajo su administración, Estados Unidos ha dejado de asumir el valor del libre comercio y adoptado un nacionalismo intenso quebrantando un elemento identitario básico estadounidense como lo es el libre comercio, una posición que ya comenzó una confrontación comercial con China, así como numerosos desencuentros con sus propios socios y aliados.

A final de cuentas, independientemente de las capacidades militares y económicas estadounidenses, el incremento y la magnitud del poder económico chino, así como sus propuestas de expansión comercial por la vía de inversiones a través del BRI, pueden empujar a numerosos países a respaldar a China sin que ello signifique una inevitable confrontación con Estados Unidos. Como señala Ian Clark (2014), las normas pueden reflejar los valores de los países dominantes siempre y cuando proporcionen beneficios a los demás. Bajo ese esquema, lo anterior implica que si los proyectos, y con ello, las normas que plantea Pekín resultan benéficos para todos los que se involucren, y además China resulta ser un líder comprometido con las valores y normas que promueve, se puede modificar el orden normativo actual y afectar el monopolio económico estadounidense.

\section{Referencias}

Adler, E. (1997). Seizing the Middle Ground: Constructivism in World Politics. European Journal of International Relations, 3(3), 319-363. doi: 10.1177/1354066197003003003

Afridi, M., Yousuf, M., \& Khan, M. (2014). Pak-China-US Triangule vis-àvis Soviet Union in Afghan War. Mediterranean Journal of Social Sciences, 5(20), 2192-2198. doi: 10.5901/mjss.2014.v5n20p2192

Anguiano, E. (2001). La diplomacia de la República Popular China. En E. Anguiano (Coord.), China contemporánea: la construcción de un país (desde 1949). México, D.F.: Colegio de México, Programa de Estudios APEC, Centro de Estudios de Asia y Africa.

44. En la presentación de la Estrategia de Seguridad Nacional de Estados Unidos, el presidente Donald Trump arremetió contra China y Rusia a quienes calificó de "competidores estratégicos" y potencias revisionistas en materia económica, asimismo, las acusó de minar la estabilidad de su país (Bordachev, 2018, p.59; El País de Madrid, 2017). 
Banco Mundial. (6 de abril de 2016). Informe anual 2016. Recuperado de http://www.iri.edu.ar/wp-content/uploads/2016/10/informe-anual2016-banco-mundial.pdf

Basrur, R. M. (2008). South Asia's Cold War: Nuclear weapons and conflict in comparative perspective. London: Routledge

BBCNews. (14 de febrero de 2011). China ya es la segunda economía del mundo. Recuperado de https://www.bbc.com>2011/02 >110213_economia_china_japon_rg

BBCMundo. (23 de enero de 2017). Donald Trump retirar a Estados Unidos del Acuerdo Transpacífico de Cooperación Económica. Recuperado de https:// www.bbc.com $>$ mundo $>$ noticiasinternaciona-38723311

Bichara, P. (8 de mayo de 2017). ¿Cuánto le debe Estados Unidos a China? Forbes. Recuperado de https://www.forbes.com.mx/cuanto-le-estadosunidos-china/

Bijian, Z. (2005). China's Paceful Rise to Great-Power Status. Foreign Affairs. Recuperado de https://www.foreignaffairs.com/articles/asia/2005-09-01/ chinas-peaceful-rise-great-power-status

Björkdahl, A. (2002). Norms in International Relations: Some Conceptual and Methodological Reflections. Cambridge Review of International Affairs, 15, 9-23. doi: 10.1080/09557570220126216

Bordachev, T. (2018). Revisionism of Powers in the Changing Historical Context: Why States Change Their Foreign Policy Behaniur on the Global Stage. Russian in Global Affairs, 16(3), 46-65. doi: 10.31278/1810-63742018-16-3-46-65.

Bouchard, J. F. (1981). United States Security Interest in China (Master's Thesis). Retrieved from https://apps.dtic.mil/dtic/tr/fulltext/u2/a109589. pdf

Bozdaglioglu, Y. (2003). Turkish Foreign Policy and Turkish Identnity: A Constructivism Approach. New York \& London: Routledge

Bravo, J., \& Sigála M. (2014). Constructivismo, En J. Schiavon, A. Ortega, M. López \& R. Velazquez, (Eds.), Teorías de Relaciones Internacionales en el Siglo xxi: Interpretaciones críticas desde México (pp. 435-453). MéxicoBenemérita Universidad Autónoma de Puebla, El Colegio de San Luis, Universidad de Baja California, Universidad Autónoma de Nuevo León, Universidad Popular Autónoma del Estado de Puebla: CIDE. 
Brzezinski, Z., \& Scowcroft, B. (2008). America and The World: Convertations on the Future of American Foreign Policy. New York: New Foundation, Basic Books.

Cafruny, A. W. (2019). Can the United States Contain China? Russia in Global Affairs, 17(1), 100-122. doi: 10.31278/1810-6374-2019-17-1-100-122

Central Intelligence Agency. (17 de agosto de 1982). Join Communique of the United States of America and the People Republic of China. Recuperado de https://www.cia.gov/library/readingroom/document/ciardp83b00551r000200010003-4

Chang, D. W. (1988). China under Deng Xiaoping: Political Economic Reform. Reino Unido: Palgrave Macmillan.

Chang, J. \& Halliday, J. (2005). Mao: The Unknown Story. Estados Unidos: Anchor Books, Penguin Random House.

Checkel, J. T. (1998). The Constructivism Turn in International Relations Theory. World Politics, 50(2), 324-348.

Cheng, J. Y. (1995). China's foreign policy in the mid-1990s. Centre for Asian Pacific Studies, Working Paper No. 28.

China's Ministry of National Defense. (2013). The People's of Republic of China. Recuperado de http://eng.mod.gov.cn/

Chow, G. C. (2004). Economic Reform and Grow in China. Annals of Economics and Finance, (5), 127-152.

Clark, I. (2014). International Society and China: The Power of Norms and Norms of Power. The Chinese Journal of International Politics, 7(3), 315340. doi: $10.1093 / \mathrm{cjip} /$ pot014

CNN. (23 de abril de 1997). China, Russia sign pact: Oppose any single world power. Recuperado de http://edition.cnn.com/WORLD/9704/23/russia. china/

CNN.China. (6 de febrero de 2004). China apunta a 'ascenso pacífico. Recuperado de http://edition.cnn.com/2004/WORLD/asiapcf/02/02/willy. column/index.html

Cohen, W. I. (2010). America's Response to China: History of Sino-American Relations. Nueva York: Columbia Univerrity Press.

Daily Telegraph. (13 de mayo de 2010). La URSS planeó un ataque nuclear contra China en 1969. Recuperado de https://www.telegraph.co.uk/news/ worldnews/asia/china/7720461/USSR-planned-nuclear-attack-on-Chinain-1969.html 
Devroy, A. \& Hoffman, D. (19 de diciembre de 1989). La Casa Blanca revela la misión anterior de China. The Washington Post. Recuperado de https:// www.washingtonpost.com/archive/politics/1989/12/19/white-housereveals-earlier-china-mission/a2f4b977-dc3a-4d8a-af53-3667ed8536d4/

De Faramiñán, J., \& De Santayana, J. (2009). El conflicto de Afganistán. España: Imprenta del Ministerio de Defensa.

De Graaff, N., \& Van Apeldoorn, B. (2018). US-China relations and the liberal world order: Contending elites, colliding visions? International Affairs, 94(1), 113-131. doi: https://doi.org/10.1093/ia/iix232

De Swielande, T. S. (2012). The Reassertion of the United States in the Asia-Pacific Region. Parameters, 42(1), 75-89. Recuperado de https:// ssi.armywarcollege.edu/pubs/parameters/articles/2012spring/Struye_de_Swielande.pdf

El Economista. (5 de abril de 2018). China responde a EU con más aranceles. Recuperado de https://www.eleconomista.com.mx/empresas/Chinaresponde-a-EU-con-mas-aranceles-20180405-0021.html

El País. (24 de abril de 1997). Rusia y China firman un acuerdo contra la hegemonía de EE UU. Recuperado de https://elpais.com/diario/1997/04/24/ internacional/861832818_850215.html

El País. (23 de diciembre de 2017). Al menos 10,000 personas murieron en la matanza de Tiannamen, según varios documentos desclasificados. Recuperado de https://elpais.com/internacional/2017/12/23/actualidad/1514064023_883857.html

El País de Madrid. (19 de diciembre de 2017). Trump ve a Rusia y China como dos amenazas a EE.UU. Recuperado de https://www.elpais.com.uy/mundo/ trump-ve-rusia-china-amenazas-ee-uu.html

Fairbank, J. K., \& Goldman, M. (2006). China: ANew History. London, England: Belknap Press

Fang C. (2016). China's Economic Growth Prospects: From Demographic Dividend to Reform Dividend. China: Social Sciences Academic Press.

Federation of American Scientists (FAS). (1997). Recuperado de http://www. fas.org

Freund, E., \& Martey, S. (2017). U.S. President Obama's China Policy: A Critical Assessment. OL PAN, 12(2), 7-29. Recuperado de: http://www. pan-ol.lublin.pl/wydawnictwa/TPol12_2/1_Larus.pdf

Friedberg, A. L. (2015). The Debate Over US China Strategy. Survival, 57(3), 89-110. doi: 10.1080/00396338,2015.1046227 
Finnemore, M. (1996). National Interest in International Society. London, Cornell University Press.

Fisac, T., \& Tsang, S. (Eds.). (2000). China en transición: Sociedad, cultura y economía. Editorial Bellaterra. Barcelona, España.

Flint, R. K., Kozumplik, P. W., \& Waraksa, T. J. (1987). The Arab-Israeli Wars, The Chinese Civil War and The Korean War. New York: Department of History United States Military Academy.

Frade, L. (1979). El conflicto fronterizo chino-soviético. Revista de Política Internacional, (162), 67-78. Recuperado de file:///C:/Users/María\%20 José/Downloads/RPI_162_067\%20(1).pdf

Gaddis, J. L. (2011). Nueva historia de la Guerra Fría. México, D.F.: Fondo de Cultura Económica.

Garrison, J. A. (2002). "Explaining Change in the carter Administration's China Policy: Foreign Policy Adviser Manipulation of the Policy Agenda". Asian Affairs, 29(2). 83-98.

Garson, R. (1997). Lyndon B. Johnson and China Enigma. Journal of Contemporary History, 32(1), 63-80. doi: 10.1177/002200949703200105

Garver, J. W. (2003). Mao's Soviet Policies. The China Quarterly, (173), 197213.

Gerson M.S. (2010). The Sino-Soviet Border Conflict: Deterrence, Escalation, and the Threat of Nuclear War in 1969. Defense Threat Reduction Agency Advanced Systems and Concepts Office (Contract Number NOOO1405-D-0500). Recuperado del sitio de internet CNA, Document Control and Distribution Section: https://www.cna.org/CNA_files/PDF/D0022974. A2.pdf

Goldman, M. (2014). Reformas post Mao; Capitalismo, Restauración y Reforma. En E. Anguiano, \& U. Pipitone (Eds.), República Popular de China: De la utopía al mercado. México: CIDE.

González, J. (2002). La política comercial de la RP China y su aceptaciónregreso a la OMC. Estudios del Pacífico, 1-30.

Han, D. G. X. (2017). China's normative Power in Managing South China Sea Disputes. The Chinese Journal of International Politics, 10(3), 269-297. doi: 10.1093/cjip/pox002

Halperin, M. H. (1966). The 1958 Taiwan Straits Crisis: A Documented History. Recuperado de https://www.rand.org/pubs/research_memoranda/ RM4900.html 
Hilali, A. Z. (2010). China's response to the Soviet invasión of Afganistan. Central Asian Survey, 20(3), 323-351. doi: 10.1080/02634930120095349 Hobson J. M. (2000). The State and International Relations. Reino Unido: University of Cambridge Press.

Hopf, T. (1998). The Promise of Constructivism in International Relations Theory. International Security, 23(1), 171-200. doi 10.2307/2539267

Hsü, I. C. Y. (2012). El Partido Comunista: 1921-1949. En E. Anguiano, \& U. Pipitone (Eds.), China, de los Xia a la República Popular (2070 a.C.-1949). Lecturas Comentadas. México: CIDE.

Hung. J. W. (2013). The rise of China and Chinese International Relations Scholarschip. Nueva York: Lexintong Books.

Hurd, I. (1999). Legitimacy and Authority in International Politics. International Organizations, 53(2), 379-408.

Jepperson, R., Wendt, A., \& Katzenstein, P. (1996). Norms, identity, and Culture in National Security. En P. Katzenstein (Ed.), The Culture of National Security: norms, and identity in World Politics (pp. 33-75). New York: Columbia University Press.

Jian, C. (1994). China's Road to Korean War: The Making of the Sino-American Confrontation. Nueva York, United States of America: University Press.

Katzenstein, P. J. (Ed.). (1996). The Culture of National Security: norms, and identity in World Politics. New York: Columbia University Press.

Keohane, R. (1988). International Institutions: Two Approaches. International Studies Quarterly, 32(4), 379-396.

Keohane, R. (2013). Stephen Krasner: Subersive Realist. En M. Finnemore, \& J. Goldstein, (Eds.), Back to Basics, State Power A Contemporary World. New York: Oxford University Press.

Kennan, G. (1947). Las fuentes de la conducta soviética. Buenos Aires, Argentina: Grupo Editor Latinoamericano

Kissinger, H. (1979). White House Years. Estados Unidos: Simon and Schuster. Krylov, L. \& Tepsurkaev, Y. (2008). Soviet Mig-15 Aces of the Korean War. Reino Unido: Osprey Publishing.

Kuisong, Y. (2000). The Sino-Soviet Border Clash of 1969: From Zhenbao Island to Sino-American Repprochement. Cold War History, 1(1), 21-52. doi: 10.1080/713999906

Leverett, F., \& Bingbing, W. (2017). The New Silk Road and China's Envolving Grand Strategy. The China Journal, 77, 110-132. doi: 10.1086/689684 
Li, D. \& Xia, Y. (2018). Mao and the Sino-Soviet Split 1959-1973: A New History. Washington, DC. : Lexington Books.

Lightbody, B. (1999). The Cold War. New York: Routledge.

Linklater, A. (1990). Beyond Realism and Marxism: Critical Theory and International Relations. New York: St. Martin's Press.

Lo, C. Y. (2018). China's Rise and the U.S. Pivot to Asia: The Implications of Trans-Pacific Partnership on the Regional Economic Architecture. En S. Fröhlich \& H. Loewen (Eds.), The Changing East Asian, Security Lanscape: Challenges, Actors and Governance (pp.1-166). Koöln, Detuchland: Springer VS.

Lüthi, L. M. (2008). The Sino-Soviet Split: Cold War in the Communist World. United Kingdom: Princeton University Press

Lynch, M. (2008). The Chinese Civil War 1945-1949. Estados Unidos: Osprey Publishing

Maley, W. (2002). The Afganistan Wars. Estados Unidos: Palgrave Macmillan. Malkasian, C. (2001). Essencial Histories: Teh Korean War, 1950-1953. Estados Unidos: Osprey Publishing

Mann, J. (1998). A history of America's curious relationships with China, from Nixon to Clinton. Estados Unidos: Vintage Edition.

Marshall, A. (1 de noviembre de 1998). Terror 'blowback' arde CIA. Independent. Recuperado de https://www.independent.co.uk/news/terrorblowback-burns-cia-1182087.html

May, E. R. (2002). 1947-1948: When Marshall Kept the U.S. Out of War in China. The Journal of Military History, 66, 1001-1010.

McCormick, J. M. (2010). American Foreign Policy \& Process. Estados Unidos: Wadsworth Publishing.

Müller-Markus, C. (2016). One Belt, One Road: el sueño chino y su impacto sobre Europa. Notes internacionals, 148, 1-6.

Naciones Unidas. (27 de junio de 1950). 83 (1950). Resolución 7 de julio de 1950. (A/RES/84/1950). Recuperado de https://undocs.org/es/S/RES/84\%20 (1950)

Naciones Unidas (UN). (2018). Recuperado de www.un.org

Nau, H. (2002). At home Abroad: Identity and Power in American Foreign Policy. Estados Unidos: Cornell University Press

Naughton, B. (1993). Deng Xiaoping: The Economist. The China Quarterly, (135), 491-514. 
Narodowski, P. (2017). Las relaciones económicas y políticas entre Estados Unidos de América y China a la luz del concepto de unipolarismo condicionado. Geopolítica(s) Revista de estudios sobre espacio y poder, 8(2), 279-297. doi: 10.5209/GEOP.56532

Lebow, R. (2001). Thucydides the Constructivist. American Political Science Review, 95(3), 547-560. doi: 10.1017/S0003055401003112

Obama, B. (17 de noviembre de 2011). Remarks By President Obama to the Australian Parliament. The White House Office of the Press Secretary. Recuperado de https://obamawhitehouse.archives.gov/the-press-office/2011/11/17/remarks-president-obama-australian-parliament

Onuf, N. G. (1989). World of Our Making: Rules and Rule in Social Theory and International Relations. Estados Unidos: Columbia University Press.

Ou, C. (2011). The U.S.' Political Challenges on China's National Security in the 21st Century's First Decade. Asian Social Sciense, 7(6), 103-109.

Pace, J. (4 de febrero de 2017). Sobre política exterior, Trump sigue hablando lenguaje de campaña. The Associated Press. Recuperado de https://apnews. com/9a5a5fbbb2ba45b2b9316e1734ec22eb

Pollack, J. D. (1984). The Lessons of Coalition Politics: Sino-American Security Relations. Estados Unidos: the Rand Corporation.

Powaski, R. (2014). La Guerra Fría: Estados Unidos y la Unión Soviética, 19171991. Barcelona, España: Editorial CRÍTICA.

Prozumenschikov, M. Y. (1996-1997). The Sino-Indian Conflict, The Cuban Misile Crisis, and Sino-Soviet Split, October 1962: New Evidence from the Russian Archives. Cold War International History Project Bulletin. Recuperado de

https://pdfs.semanticscholar.org/f6f9/7f74ea9b408ad3f379cb3903feda32 43d0fd.pdf

Rabena, E. (2018). Apuntes geopolíticos de los últimos ejercicios militares de la OCS. Instituto de Estudios Políticos y Estratégicos. Recuperado de https:// www.idepe.org.pe/single-post/2018/10/25/Apuntes-geopoliticos-de-losultimos-ejercicios-militares-de-la-OCS

Reus-Smit, C. (1996). Constructivism, En S. Burchill, A. Linklater, R. Devetak, J. Donnelly, M. Paterson, C. Reus-Smit \& J. True (Eds.), Theories of International Relations (pp.1-289). New York, The United States of America: Palgrave Macmillan.

Reus-Smit, C. (2004). American Power and World Order. London: Polity Press. 
Roberts, P., Levine, S., Vámos, P., Kaple, D., Friedman, J., Stiffler, D., \& Lüthi, L. (2010). FORUM: Mao, Khrushchev, and China's Split with the USSR: Perspectives on The Sino-Soviet Split. Journal of Cold War Studies, 12, 120-165. doi:10.1162/jcws.2010.12.1.120

Rossabi, M. (2014). A History of China. Estados Unidos: Wiley Blackwell.

Roy, D. (1997). The Foreign Policy of Great-Power China. Contemporary Southeast Asia, 19(2), 121-135.

Ray, J. (2008). American Foreign Policy and Political Ambition. Washington D.C: COPRESS.

Santa-Cruz, A. (2000). Un debate teórico empíricamente ilustrado: la construcción de la soberanía japonesa, 1853-1902. Guadalajara, Jalisco, México: Universidad de Guadalajara.

Sarker, N. I., Hossin, A., Yin, X., \& Sarkar, K. (2018). One Belt One road Iniciative of China: Implication for Futures of Global Development. Modern Economy, 9(4), 623-638. doi: 10.4236/me.2018.94040

Sinha, R. (2003). Sino-American Relations: Mutual Paranoia. Londres, Reino Unido: Palgrave macmillan

Stockholm International Peace Research Institute (SIPRI). (2018). Recuperado de https://www.sipri.org/

Stueck, W. (1995). The Korean War: An International History. Estados Unidos: Princeton University Press.

Tayler, F. M., \& Medeiros E. S. (2006). China's Search for Assured Retaliation. International Security, 30(4), 7-44.

The Learning Network. (25 de octubre de 2011). 25 de octubre de 1971, República Popular de China en Taiwán fuera, en la ONU. Recuperado de https:// learning.blogs.nytimes.com/2011/10/25/oct-25-1971-peoples-republicof-china-in-taiwan-out-at-un/

The White House. (28 de mayo 2014). Remarks by the President at the United States Military Academy Commencement Ceremony. Recuperado de https://obamawhitehouse.archives.gov/the-press-office/2014/05/28/ remarks-president-united-states-military-academy-commencementceremony

Tiezzi, S. (6 de marzo de 2014). El creciente presupuesto de defensa de China no es tan aterrador. The Diplomat. Recuperado de https://thediplomat. com/2014/02/chinas-growing-defense-budget-not-as-scary-as-youthink/ 
Tyler, P. (1999), A Great Wall: An Investigative History. Nueva York: Century Fondation Book, Public Affairs.

United States. Congress. Senate. Committee on Finance. (1991). Extending most-favored-nation status for China: hearing before the Committee on Finance United States Senate, One Hundred First Congress, second session, June 20, 1990. Washington: U.S. G.P.O.

U.S. DEPARTMENT OF STATE. (1969). Intelligence Note 139 (AuthorityNND909000). Recuperado de https://nsarchive2.gwu.edu//NSAEBB/ NSAEBB49/sino.sov.1.pdf

Waltz, K. (2000). Structural Realism after Cold War. Quarterly Journal: International Security, 25(1), 5-41.

Wang, D. (2013). U.S.-China Trade. 1971-2012: Insights into the U.S.-China Relationship. The Asian-Pacific Journal/Japan Focus, 11(4), 1-15.

Wang J. (2015). China's Evolving Attitudes and Approaches toward UN Collective Security. En G. J. Ikenberry, W. Jisi, Z. Feng (Eds.), America, China, and the Struggle for World Order. Asia Today (pp.103-131). New York: Palgrave Macmillan.

Weldes, J. (1996). Constructing National Interest. European Journal of International Relations. 2(3), 275-318. doi: 10.1177/1354066196002003001

Wendt, A. (1992). Anarchy is what States Make of it: The Social Construction of Power Politics. International Organization, 46(2), 391-425.

Wendt, A. (1999). Social Theory of International Politics. London, United Kingdom: Cambridge University Press.

Wenzao, T. (2004). Sino-american Relations During the George W. Bush Administration. American Foreign Policy Interest, 26, 409-413.

Ximbo, W. (2001). To be a Enlightened Superpower. The Washington Quarterly, 23(3), 63-71.

Xuetong, Y. (2019). The Age of Uneasy Peace: Chinese power in Divided World. Foreign Affairs. Recuperado de https://www.foreignaffairs.com/articles/ china/2018-12-11/age-uneasy-peace

Zhou, J. (2019). China's Core Interest and Dilemma in Foreign Policy Practice. Pacific Focus, 34(1), 31-54. doi: 10.1111/pafo.12131

Zubok, V., \& Pleshakov C. (1996). Inside the Kremlin's Cold War: From Stalin to Khrushchev. London, England: Harvard University Press. 